Board of Governors of the Federal Reserve System

International Finance Discussion Papers

Number 1093r

This Version: May 2016

Original Version: November 2013

\title{
Surprise and Uncertainty Indexes:
}

\section{Real-Time Aggregation of Real-Activity Macro Surprises}

\author{
Chiara Scotti
}

NOTE: International Finance Discussion Papers are preliminary materials circulated to stimulate discussion and critical comment. References in publications to International Finance Discussion Papers (other than an acknowledgment that the writer has had access to unpublished material) should be cleared with the author or authors. Recent IFDPs are available on the Web at www.federalreserve.gov/pubs/ifdp/. This paper can be downloaded without charge from Social Science Research Network electronic library at http://www.ssrn.com/. 


\title{
Surprise and Uncertainty Indexes: Real-time Aggregation of Real-Activity Macro Surprises
}

\author{
Chiara Scotti \\ Federal Reserve Board
}

\begin{abstract}
I construct two daily, real-time, real activity indexes for the United States, Euro area, the United Kingdom, Canada, and Japan: (i) a surprise index that summarizes recent economic data surprises and measures optimism/pessimism about the state of the economy, and (ii) an uncertainty index that measures uncertainty related to the state of the economy. The surprise index preserves the properties of the underlying series in affecting asset prices, with the advantage of being a parsimonious summary measure of real-activity surprises. For the United States, the real-activity uncertainty index is compared to other proxies commonly used to measure uncertainty to show that when uncertainty is strictly related to real activity, it has a potentially milder impact on economic activity than when it also relates to the financial sector.
\end{abstract}

Keywords: Business cycle, Dynamic factor model, State space model, Forecasting weights

JEL: C38, E32

Email address: chiara.scotti@frb.gov I would like to thank for their useful comments Boragan Aruoba, David Bowman, Celso Brunetti, Domenico Giannone, Raffaella Giacomini, Rob Martin, Andrew Patton, Barbara Rossi, Jonathan Wright, Clara Vega as well as anonymous referees and various participants of conferences and seminars: 2012 Computing in Economics and Finance; 2012 European Meeting of the Econometric Society; 2012 Conference on Real-Time Data Analysis, Methods, and Applications at the Philadelphia Fed; 2012 NBER-NSF Time Series Conference; Third IFO conference on Macroeconomics and Survey Data; 2013 Econometric Society Australasian Meeting; Dallas Fed Conference on The Causes and Macroeconomic Consequences of Uncertainty; Boston College; and Board of Governors of the Federal Reserve System. For outstanding research assistance I thank Rebecca DeSimone, Eric English, Olivia Kim, and Margaret Yellen. The views expressed in this paper are solely the responsibility of the author and should not be interpreted as reflecting the view of the Board of Governors of the Federal Reserve System or of any other person associated with the Federal Reserve System. (Chiara Scotti) 


\section{Introduction}

This paper proposes a new methodology to construct two real-time, real activity indexes: (i) a surprise index that summarizes recent economic data surprises and measures deviation from consensus expectations and (ii) an uncertainty index that measures uncertainty related to the state of the economy. The indexes, on a given day, are weighted averages of the surprises or squared surprises from a set of releases, where the weights depend on the contribution of the associated real activity indicator to a business condition index à la Aruoba et al. (2009). The surprise index measures whether agents are ex-post more optimistic or pessimistic about the real economy than indicated by actual data releases 11 A positive (negative) reading of the surprise index suggests that economic releases have on balance been higher (lower) than consensus, meaning that agents were more pessimistic (optimistic) about the economy. The uncertainty index measures how uncertain agents are ex-post about current real activity conditions. A greater (smaller) reading of the uncertainty index suggests that agents have on balance been more (less) uncertain about the state of the economy. I apply this methodology to construct indexes for the United States, Euro Area, the United Kingdom, Canada, Japan, and an aggregate of the five countries over the 2003-2012 period.

The Aruoba, Diebold, and Scotti (ADS) index maintained by the Federal Reserve Bank of Philadelphia has proven to be a successful economic indicator and as such it has been classified by the Wall Street Journal among the 50 economic indicators that really matter (Constable and Wright (2011)) and has been added by Bloomberg to the data that can be followed in real time through its platform (ADS BCI Index) ${ }^{2}$ The ADS index measures the state of the economy and serves as a summary statistic of the information market participants have received thus far about real activity. However, in efficient markets, asset prices react to new information. Thus it is important to measure the surprise

1 Ex-post optimism or pessimism differs from ex-ante optimism or pessimism. If we consider the weather, for example, the optimal, model-consistent forecast for the temperature tomorrow could be 15 degrees Fahrenheit. I could be ex-ante optimistic and expect it to be 20 degrees Fahrenheit. If the forecast turns out to be wildly wrong, and the temperature turns up at a toasty 25 degrees, I was still ex-ante optimistic, even though, ex-post, my forecast looks pessimistic. Ex-post optimism or pessimism is neither necessary nor sufficient to say anything about ex-ante beliefs. Another definition that I think captures well these measures is realized optimism or pessimism.

${ }^{2}$ http://www.philadelphiafed.org/research-and-data/real-time-center/business-conditionsindex/ 
component of the information that has just arrived and the uncertainty surrounding that information. To this end, the surprise index presented in this paper aggregates the information contained in the surprises to construct a summary measure of the deviation of the real economy from consensus expectations, and the uncertainty index quantifies economic uncertainty, which is otherwise challenging to measure. The indexes are not competitors but complements to the existing business condition indicators such as the ADS index and to existing uncertainty indexes.

This paper relates to several branches of the literature. First and foremost is the uncertainty literature, which has thrived in recent years. Because uncertainty is not observable, a number of proxies have been used to measure it, ranging from stock market realized and implied volatilities (Bloom (2009)), to the cross-sectional dispersion of survey-based forecasts (Bachmann et al. (2013)), the frequency of newspaper references to economic policy uncertainty (Baker et al. (2015)), or the common variability in the purely unforecastable component of the future value of a big number of variables (Jurado et al. (2015)). However, these measures tend to combine economic uncertainty with other notions. For example, stock return volatility combines information about stock market volatility with economic uncertainty, and forecast disagreement could measure divergence of opinions among forecasters rather than just the underlying uncertainty about the economy. My paper contributes to this literature by providing a daily macroeconomic information uncertainty measure which quantifies the part of uncertainty that specifically relates to the state of the real economy. It also contributes by helping to disentangle the impact of purely macro uncertainty from more general uncertainty. The index is daily in that it gets updated every time new information about the state of the economy gets released. Second, this paper relates to those papers that study the impact of news surprises on asset price such as Andersen et al. (2003), Andersen et al. (2007), and Gilbert et al. (2012), and contributes to this literature by providing a parsimonious summary measure of real-activity macroeconomic surprises. The paper also relates to papers that use similar factors models to extract a business condition index (Aruoba et al. (2009), and Banbura et al. (2010) among others). It also employs the idea of forecasting weights developed in Koopman and Harvey (2003) and applied by Banbura and Runstler (2010) and Camacho and Perez-Quiroz (2009), among others, to study the impact of news releases on GDP forecast revisions.

In order to construct the surprise and uncertainty indexes, I first employ a 
dynamic factor model to estimate monthly business condition indexes for the aforementioned countries and compute the weights representing the contribution of the economic indicators to these business condition indexes. I then use those weights to average the surprises or squared surprises in order to construct the surprise and the uncertainty indexes, respectively. The weights depend on (i) the time elapsed since the release of the associated information and (ii) the unbalancedness pattern of the underlying releases. The former is a time decay feature that reduces the contribution of each surprise over time. The latter is a missing data characteristic that sets to zero the contributions of an indicator in months in which no data is available.

I find that surprise indexes tend to be negative during the recession associated with the 2008 financial crisis, the so-called Great Recession, suggesting that agents were more optimistic about the real economy than it warranted 3 There appear to be other episodes when the indexes are negative. Of note are several declines in the euro-area surprise index after 2011, the sharp drop in the Japanese surprise index after the March 2011 earthquake, and the prolonged low levels of the U.K. index in 2010 and 2011. On the other hand, there are also several instances where the surprise indexes are positive, especially coming out of the recession in the United States, the United Kingdom and Canada. I show that the surprise index preserves the properties of the underlying series in affecting asset prices, with the advantage of being a parsimonious summary measure of real-activity surprises. In light of this, Demiralp et al. (2013) make use of it as a control variable when investigating the effects of political commentaries on policy rate decisions and policy expectations in the United States and the Euro Area, and find it to be significant determinant of policy expectations. Similarly, Brunetti et al. (2013) employ it as a control variable in studying the impact of speculation activity in the crude oil market.

The uncertainty indexes tend to be higher during recession periods. Interestingly, the euro-area uncertainty index reaches its highest values just before and after the 2008-2009 recession, suggesting that agents were more uncertain about the economy as the Euro Area was entering and exiting the recession. The daily U.S. uncertainty index looks somewhat similar to the U.S. stock market implied volatility as measured by the VIX. Implied volatility, a forward-looking

\footnotetext{
${ }^{3}$ Unfortunately, we are not able to see whether this is a characteristic of all recessions because the surprise indexes only start in 2003 and hence only cover one recession episode. Expectation data are available from Bloomberg for all countries since 2003.
} 
measure, is computed from option prices. The uncertainty index, a historical measure, is calculated from current and past macroeconomic news surprises. The former is a wider measure that combines information about risk aversion and future stock market volatility/uncertainty, and to the extent that these two move with news surprises, the VIX also contains information about current and future economic uncertainty. Although understanding the exact linkages goes beyond the scope of this paper, I also decompose the VIX following Bakaert et al. (2013) into stock market uncertainty and variance risk premium, and observe that the VIX patterns are mainly driven by the Bakaert et al. (2013) stock market uncertainty during the period analyzed 4

In a bivariate VAR exercise with employment and uncertainty proxies for the United States over the last decade, I find that, when uncertainty is strictly related to real activity as measured by the real-activity uncertainty index, it has a potentially milder impact on economic activity. Just flipping the argument, when uncertainty is more generally related to economic and financial conditions as measured by the VIX or Bakaert et al. (2013) stock market uncertainty proxy, its impact on real-activity variables seems to be stronger and faster. This finding supports recent work by Caldara et al. (2013) which finds that the financial channel is key in the transmission of uncertainty shocks. Of course, the different impact could also be more generally due to the fact that the VIX measures a more wide-ranging notion of uncertainty.

The surprise and uncertainty indexes tend to be negatively correlated, meaning that bad news occurs together with increased volatility $5^{5}$ This result is similar to the inverse relationship between first and second moments of asset returns found in the financial literature, a phenomenon that Fostel and Geanakoplos (2012) provide a theoretical explanation for, together with explaining a decrease in leverage.

The remainder of the paper is organized as follows: section 2 presents the data and the rationale behind using Bloomberg forecasts; section 3 presents the details of the model's forecasting weights and the construction of the surprise and uncertainty indexes; section 4 covers the estimation details; section 5 presents the results; section 6 shows some applications; and section 7 concludes.

\footnotetext{
${ }^{4}$ The correlation between the daily U.S. uncertainty index and the VIX is 53 percent over the sample period analyzed.

${ }^{5}$ The correlation ranges between -0.26 to -0.45 for the United States, Euro Area, the United Kingdom and Japan, whereas it is positive in Canada over the sample period analyzed in the paper.
} 


\section{Data}

Before getting into the model, this section presents information about the data used to construct the surprise and uncertainty indexes. I use two different types of data: the actual first release of the macroeconomic variable, say gross domestic product (GDP) or nonfarm payroll, and its forecast as measured by the Bloomberg median expectation. Of note, Bloomberg expectations generally do not run the risk of being stale forecasts as they can be updated until one hour before the data release. The forecast that I use is the latest one recorded by Bloomberg 6 The actual releases of macroeconomic variables are used to estimate the underlying factor model from which I gather the weights. The difference between actual releases and Bloomberg expectations, also known as news surprise or forecast error, is then used together with the weights to construct the surprise and uncertainty indexes. In what follows, I describe the details of the data and study some of the properties of the news surprises.

The analysis covers five countries: the United States, the Euro Area, the United Kingdom, Canada, and Japan. I use five indicators for each country, except the United States for which I use six. Several considerations guide the choice of variables. First, I want to use those variables that are regarded as the main real activity indicators and as such followed by the business community, governments, and central banks as indication of the state of the economy. Second, I choose indicators for which analysts form expectations that are publicly available (see Table B1 in the online Appendix) 7

The analysis for the surprise and uncertainty indexes covers the period from May 15, 2003 through March 31, 2016. However, a longer dataset is used to estimate the underlying business condition indexes: January 1980 to March 31, 2016, except for the Euro area where the sample starts in January 1985.

The first indicator is quarterly real GDP. For each country, the first GDP release for the corresponding quarter is used. The second indicator is industrial production (IP), which is a monthly indicator. The third indicator is employees on nonagricultural payrolls, when available, or the unemployment rate 8 The

\footnotetext{
${ }^{6}$ The survey is done on a rolling basis and the Bloomberg news team run tables every weekday morning, as they get the forecasts. Economists can usually make changes up to an hour before release time.

${ }^{7}$ The table lists the indicators, together with their frequency, publication lags and transformations that I use to construct the real activity factor. The two rightmost columns list the source of the data series that I use to construct the factor, and the corresponding Bloomberg data series that I use to construct the surprise and uncertainty indexes.

${ }^{8}$ Employment data and expectations are available only for the United States and Canada.
} 
former tends to be more timely than the latter, but unfortunately it is not available for all countries 99 The fourth indicator is retail sales, which is another monthly variable. The fifth indicator is a survey measure of the manufacturing sector or the overall economy (composite) depending on the availability of the Bloomberg forecast. I use the ISM manufacturing index for the United States, the composite PMI for the Euro Area, the manufacturing PMI for the United Kingdom and Canada (Ivy survey), and the Tankan survey for Japan. The Tankan survey is a quarterly series, whereas the other surveys are all monthly 10 Although monthly series are generally preferred when available, the Tankan survey has the advantage of being very timely, as it is released on average four days before the end of the quarter it refers to 11 The average publication lag for the other series vary a lot as shown in table B1 in the online Appendix. Survey measures are the most timely of all: the euro-area Flash composite PMI is the first indicator to be released, followed by the Japanese Tankan survey, the U.S. ISM and the U.K. PMI. On the other hand, GDP and IP data tend to be the last information to be released.

The additional indicator for the United States is the Bureau of Economic Analysis (BEA) personal income. Household income or personal income are generally available for the other countries but because their expectation is not, I drop them from the dataset.

As already mentioned, while the announcement itself is used in constructing the real activity factor, the news surprise, that is the difference between announcement realizations $\left(y_{t}^{i}\right)$ and their corresponding Bloomberg expectations $\left(E\left[y_{t}^{i} \mid \mathcal{F}_{t}\right]\right)$, is used in constructing the surprise and uncertainty indexes. Because units of measurement vary across macroeconomic variables, I standardize the resulting surprises by dividing each of them by their sample standard deviation $\left(\sigma^{i}\right)$. The standardized news surprise associated with the macroeconomic

\footnotetext{
For the other countries we use the unemployment rate.

${ }^{9}$ To avoid confusion, because for all the indicators a higher number means that the economy is doing well, I feed the negative of the unemployment rate into the model.

${ }^{10}$ For Canada, Bloomberg used to provide expectations for the non-seasonally-adjusted IVY index, but as of March 2011, it started to provide expectations for the seasonally adjusted series. I splice the two series together being aware of the break point.

${ }^{11}$ The Tankan survey has an average publication lag of -4 days, but only Q4 numbers are released before the end of the quarter (around mid-December). Other releases occur at the beginning of the following quarter.
} 
indicator $y^{i}$ at time $t$ is therefore computed as:

$$
s_{t}^{i}=\frac{y_{t}^{i}-E\left[y_{t}^{i} \mid \mathcal{F}_{t}\right]}{\sigma^{i}} .
$$

\subsection{News Surprises}

Market participants watch, and react to, scheduled macroeconomic announcements because these announcements potentially contain new information that was not previously incorporated into market participants' expectations about the state of the economy. Several studies have looked into the forecast efficiency, or rationality, of market expectations. Under rationality, the surprise component, measured as difference between the actual release and its forecast, should truly represent "news," meaning that market agents optimally use available information in forming their forecasts, and therefore the forecast error should be orthogonal to information available when the forecast is produced. This is equivalent to testing whether the error term $\varepsilon_{t}^{i}$ is orthogonal to the forecast $y_{t}^{i, f}=E\left[y_{t}^{i} \mid \mathcal{F}_{t}\right]$ in the equation

$$
y_{t}^{i, f}=y_{t}+\varepsilon_{t}^{i} .
$$

In particular, testing for forecast efficiency boils down to testing that $\alpha^{i}=\beta^{i}=$

0 in the regression

$$
s_{t}^{i}=\alpha^{i}+\beta^{i} y_{t}^{i, f}+u_{t}^{i}
$$

where $s_{t}^{i}=y_{t}^{i}-y_{t}^{i, f}$ is the forecast error, a.k.a news surprise. This is sometimes known as the Mincer-Zarnowitz test (Mincer and Zarnowitz (1969)). Several earlier papers have applied these tests mainly using data revisions (among others, see Croushore and Stark (2001) and Faust et al. (2005)). Table 1 reports evidence from the baseline tests of forecast rationality - tests of the hypothesis that $\alpha^{i}=\beta^{i}=0$ in equation (3). As can be seen in the middle columns, $\alpha^{i}$ and $\beta^{i}$ are very often significantly different from zero and the $\mathrm{F}$ test fails to reject the null hypothesis that $\alpha^{i}=\beta^{i}=0$ only in $1 / 3$ of the cases.

But given that Bloomberg median forecasts are not efficient, why are they so important? Why do I use them rather than using efficient forecasts that I could construct within the factor model? The answer is simple: financial markets react neither to my own private forecast nor yours; financial markets react to Bloomberg forecasts, which are public and everyone can see.

A wide literature has documented the asset price response to macroeconomic 
news announcements. Andersen et al. (2007) and Gilbert et al. (2012) among others have looked into this question. Table 2 displays the results of univariate regressions of foreign exchange returns on the individual macro announcement surprises over the sample period 2003-2012. These results do not necessarily correspond to what reported in the existing literature because of the different samples used. However, they clearly state the point that Bloomberg forecasts (and surprises) are important because financial markets react to them.

\section{The Model}

I use a standard dynamic factor model at a monthly frequency which explicitly accounts for missing data and temporal aggregation (details can be found in the appendix). With it, each of the real-activity variables is used to extract information about the common (unobserved) factor.

\subsection{Forecasting Weights}

The contribution of each real-activity variable to the determination of the factor represents the weight applied to construct the surprise index. As shown in Koopman and Harvey (2003), the weights $w_{j}\left(\alpha_{t \mid t}\right)$ are used to calculate the estimator of the state vector based on information available as of time $t$ and can

therefore be used to compute the contribution of variable $y_{j}^{i}$ in forecasting the factor $x$ at time $t$ :

$$
x_{t \mid t}=\sum_{j=1}^{t-1} w_{j}\left(\alpha_{t \mid t}\right) y_{j}
$$

As in the previous section, $y_{t}$ can contain vectors of monthly or quarterly series $\left(y_{t}^{M}, y_{t}^{Q}\right)$. Each series is indicated by $y^{i} . w_{j}$ is the vector of weights at time $t$ referring to the monthly and quarterly series.

I consider the real-time release schedule of each real activity series $y^{i}$. For example, if I want to calculate the factor for the month of March 2012, information about that month will be released gradually. In the United States, the ISM index will be the first series to be released, most likely followed by employment, retail sales, industrial production, and personal income. The advance reading of GDP for the first quarter (i.e. the one which includes January) will be released with an average delay of 29 days from the end of the quarter. Based on this real-time schedule, I can recursively compute the underlying unobserved factor at time $t$ based on the data availability until day $t$, that is $x_{t \mid t}$. Equation (4) displays the factor at time $t$ as a weighted average of the data $y$ released 
between day 1 and $t$. The weights implicitly display a time decay feature with more recent data exhibiting higher importance in determining the factor.

For each data series included in $y$, say $y^{i}$, there exist a time series of weights $w_{j}^{i}$, so that cumulative forecast weights can be computed as in Banbura and Rünstler (2010)

$$
w_{c u m}^{i}=\sum_{j=1}^{t} w_{j}^{i} .
$$

Forecast weights do not depend on time $t$, but depend on the forecast horizon and the real-time release pattern of the data. In this paper, I abstract from data revisions.

An alternative to using the forecast weights as outlined above, would be to use the weights as described in Banbura and Modugno (2014). In this case, the weights would have a different interpretation, as they would represent the contribution of the news releases to the factor revision from period $t$ to $t+1$. The Banbura and Modugno (2014) weights are represented by the $b_{\nu+1, j}$ in:

$$
E\left[x_{t}^{i} \mid \Omega_{\nu+1}\right]-E\left[x_{t}^{i} \mid \Omega_{\nu}\right]=\sum_{j=1}^{J_{\nu+1}} b_{\nu+1, j}\left(y_{t}-E\left[y_{t}^{i} \mid \Omega_{\nu}\right]\right)
$$

where $E\left[x_{t}^{i} \mid \Omega_{\nu+1}\right]-E\left[x_{t}^{i} \mid \Omega_{\nu}\right]$ represents the revision to the factor implied by the new data release, $\left(y_{t}-E\left[y_{t}^{i} \mid \Omega_{\nu}\right]\right)$ is the news surprise, and $\Omega_{\nu}$ and $\Omega_{\nu+1}$ are two consecutive data vintages with $\Omega_{\nu} \subset \Omega_{\nu+1}$. In the Banbura and Modugno (2014) framework, $E\left[y_{t}^{i} \mid \Omega_{\nu}\right]$ is the model implied expectation of the variable $y$, while in my framework $E\left[y_{t}^{i} \mid \Omega_{\nu}\right]$ would be the Bloomberg expectation for the macro variable $y$. The advantage of their set-up is that the weights represents the impact of the news release of a variable $y$ on the underlying factor forecast, rather than the importance of the underlying series $y$ in determining the factor. The drawback, however, is that the weight $b$ is practically the Kalman gain and as such, this set-up does not provide me with a time series of the weights similar to what I have in my framework. A way to overcome this issue could be to apply some arbitrary time decay feature similar to what applied by Citigroup to construct the so-called "Citigroup Economic Surprise Indexes." These indexes are defined as weighted historical standard deviations of data surprises where the weights of economic indicators are derived from the announcement's impact that these data surprises have on foreign exchange markets to which a subjective decay function is applied. 


\subsection{The Surprise Index}

I construct the surprise index starting from equation (4). With the idea that forecast weights represent the importance of the series in determining the underlying unobservable factor, I use those same weights to combine the standardized surprises so that the surprise index $\mathcal{S}$ at time $t$ is:

$$
\mathcal{S}_{t}=\sum_{j=1}^{t} w_{j} s_{j}
$$

where $s_{j}=\left(s_{t}^{M}, s_{t}^{Q}\right)^{\prime}$ contains the vectors of the standardized surprise $s^{i}$ corresponding to each data series $y^{i}$. ${ }^{12}$ In the application, I construct the underlying series that feed into the factor so that a higher (lower) number means that the economy is doing better (worse). Likewise, I construct each surprise such that a positive surprise means good (bad) news for the economy. This implies that the weights should be positive.

The surprise indexes are daily: every time new information becomes available, i.e. new data are released, the surprise index gets updated. If there are no new data, the index is equal by construction to its value on the previous day. Of course, more data releases imply that the surprise index gets updated more frequently.

\subsection{The Uncertainty Index}

The uncertainty index is computed starting from equation (4) and averaging squared surprises

$$
\mathcal{U}_{t}=\sqrt{\sum_{j=1}^{t} w_{j} s_{j}^{2}} .
$$

The link with realized volatility is straightforward. Just like realized volatility is computed as the square root of the average of squared returns, $R V_{n}=$ $\sqrt{\frac{1}{n} \sum_{t=1}^{n} r e t_{t}^{2}}$, the uncertainty index is computed as the square root of the weighted average of the squared surprises ${ }^{13}$ The weights are not simply $1 / n$

\footnotetext{
${ }^{12}$ Because $s$ and $w$ are vectors, I am practically aggregating over variables (through the product of $s$ and $w$ ) and over time (with $\sum_{j=1}^{t}$ ).

${ }^{13}$ Realized volatility is more precisely defined as $v o l=\sqrt{\frac{1}{n} \sum r e t_{i}^{2}-\left(\frac{1}{n} \sum r e t_{i}\right)^{2}}$ but because the second term, the average return, tends to be zero it is frequently dropped. Similarly, we abstract from using the second term, $\left(\sum_{j=1}^{t} w_{j} s_{j}\right)^{2}$ in the definition of the uncertainty index. In practice, this term is very close to zero.
} 
but are time varying. Moreover, unlike the volatility which is computed on one instrument at a time using the history from $t=1, \ldots, n$, the uncertainty index is computed across different instruments/surprises as well as across time.

As mentioned in the introduction, these surprise and uncertainty indexes are ex-post, realized measures. Moreover, these indexes measure how optimistic / pessimistic or uncertain agents are about recent economic conditions. Bloomberg forecasts are constructed in such a way that contributors can submit and continuously revise their forecasts until one hour before the data release. The forecasts that I use are screen-shots of the latest submitted forecasts. For example, if we consider nonfarm payroll, a contributor can submit her forecast until 7:30 am ET of the first Friday of the month for the release of nonfarm payroll referring to the previous month. In this sense, these measures are backward looking measures as they use today's best guess (forecast) about the state of the economy in the recent past. Because the Bloomberg forecasts refer to the latest macroeconomic statistics only, it is not possible to compute these measures for different horizons, say $t+1, t+2, \ldots$ In fact, the macroeconomic announcements analyzed in this paper are all released with a reporting lag, meaning that they are announced after the end of the period they refer to. Practically, this uncertainty measure can even be considered as a nowcasting/backcasting exercise in that it uses weighed forecast errors from the recent past.

Similarly to the surprise indexes, the uncertainty indexes are also daily in that they get updated every time new information become available.

\section{Estimation}

The construction of the indexes requires three steps:

(i) estimation of the state space model,

(ii) determination of the weights $w_{j}$ as defined in equation (4) and

(iii) construction of the indexes as for equations (7) and (8).

For step (i), the estimation of the model described in the online Appendix $\mathrm{A}$ and $\mathrm{B}$ requires estimation of the parameters $\theta=\{\mu, Z, T, \Sigma\}$. The missing data pattern complicates the estimation of the model. Missing data occur both because the data are at different frequencies and because indicators are released

at different times after the end of the reference period (ragged edge). A number of papers have dealt with different frequencies and missing observations either 
within a Kalman filter framework (see among others Aruoba et al. (2009), Giannone et al. (2008), and Banbura and Modugno (2014)) or within a mixed data sampling (MIDAS) regression framework (Andreou et al. (2011)). I estimate the parameters by maximum likelihood implemented by the Expectation Maximization (EM) algorithm as proposed by Doz et al. (2012) and extended by Banbura and Modugno (2014) to deal with missing observations and idiosyncratic dynamics 14 The EM algorithm iterates over two steps: in the expectation step, the log-likelihood conditional on the data is calculated using the estimated parameters from the previous iteration; in the maximization step, the parameters are re-estimated by maximizing the expected log-likelihood with respect to $\theta$. Following Doz et al. (2011) and Doz et al. (2012), the initial parameters $\theta(0)$ are obtained through principal components and the iteration between the two steps is stopped when the increase in likelihood between two steps is small.

In step (ii), once the parameters $\theta$ are estimated, the weights can be computed by running the algorithm defined in Koopman and Harvey (2003) to get the smoothed weights. The history of weights $w_{j}\left(\alpha_{t \mid t}\right)$ for $j=1, \ldots, t$ is computed in real time for any $t$ based on the information available up until that time.

Finally, in step (iii), the surprise and uncertainty indexes are computed based on (7) and (8).

Each country is estimated separately. The estimation of the underlying business condition index is based on the longest common sample across countries (1980-2012), except for the euro area for which not enough indicators are available before 1985 . The Kalman filter is then run based on the estimated parameters in a real time framework (i.e. based on data that are released sequentially), and steps (ii) and (iii) are repeated to get the smoothed weight matrix and the real-time surprise and uncertainty indexes for each day from May 15, 2003 to September 30, 2012 15 Step (i) is run over the entire sample, unlike steps (ii) and (iii), because for countries in which data series become available later in the sample estimates are not accurate at first 16 For the United States, where there are no issues of data availability, there are no significant differences in the

\footnotetext{
${ }^{14}$ I thank Banbura, Giannone and Reichlin for sharing their EM codes.

${ }^{15}$ The surprise index is computed on a shorter sample due to the limited availability of expectation data for all the countries.

${ }^{16}$ The underlying real activity factor is estimated on the full sample to avoid parameter instability problems due to the fact that, for some of the countries, some macroeconomic releases become available later in the sample (namely retail sales and PMI series).
} 
surprise indexes constructed according to the two methodologies ${ }^{17}$

\section{Results}

Here I discuss the results following the steps described in the estimation section.

\subsection{Real Activity Indexes}

The real activity indexes that I estimate based on the indicators described above are displayed in figure 1. As mentioned, I use a longer history for the estimation of these factors in order to have more reliable estimates. The figure shows the latest factors, which include information as of March 31, 2016, for the United States, the Euro Area, the United Kingdom, Canada, Japan, and an aggregate of the five countries.

The average value of each index is zero by construction. Therefore, a value of zero is interpreted as average economic activity for that country, whereas progressively bigger positive values indicate progressively better-than-average conditions and progressively more negative values indicate progressively worsethan-average conditions. Importantly, average conditions differ across countries. For example, a value of zero for Japan corresponds to a number akin to 0.7 percent annual real GDP growth while a value of zero in the United States corresponds to around 2.5 percent annual real GDP growth. The shaded areas in the panels represent official recessions as defined by the NBER, CEPR, and ECRI. The indexes fall sharply during recessions and tend to reach relatively high values during good times, for example the late 1990s. As expected, the U.S. business condition index is very similar to the ADS index maintained by the Federal Reserve Bank of Philadelphia, with the difference that the ADS index is daily and also includes weekly data such as initial jobless claims. Because the other countries do not have relevant weekly data, I opted here for a monthly frequency. The last panel shows the aggregate business condition index, which is created by aggregating the other indexes weighing them by each country's GDP.

\footnotetext{
${ }^{17}$ That means, running (i), (ii) and (iii) in real time versus running (i)over the entire sample, and (ii) and (iii) in real time does not give significant differences for the United States.
} 


\subsection{Weights}

To gauge the importance of the various indicators in constructing the surprise and uncertainty indexes, I consider two different standpoints in analyzing the weights: (i) I construct the cumulative weights as in equation (5) and (ii) I analyze, at each time $t$, the vector of $t \times 1$ weights, $w_{t}^{j}$, that are multiplied by the announcements to get the time $t$ surprise index based on equation (7).

To be clear, for $t=\widetilde{t}$, the variable $w$ that represents the weights in equation (7) is a matrix of dimension $\widetilde{t} \times M Q$ which contains those weights applied to all the announcements available up to time $\widetilde{t}$ that are used in the construction of the index. The sum of these weights over time represents the cumulative weight for indicator $i$ at time $\widetilde{t}$, that is $w_{c u m}^{i}=\sum_{j=1}^{\widetilde{t}} w_{j}^{i}$.

Average cumulative weights computed over the 2003-2016 sample show that employment (or unemployment) and industrial production have the highest value in the United States, the Euro Area, and in the United Kingdom. In Canada, most of the weight is concentrated on employment. In Japan, industrial production is the most important series followed by unemployment and retail sales ${ }^{18}$ Cumulative weights, however, are not constant over time and therefore looking at their mean is not enough. They are affected by the pattern of missing observations due to the different release schedules of the underlying indicators (ragged edge). Figure 2 shows the evolution of the cumulative forecast weights $w_{c u m}^{i}$ for each indicator over the first quarter of 2012. Each panel in the figure displays the weights for a specific country. A clear pattern stands out: as soon as new information about an indicator becomes available, the contribution of that particular indicator increases. So, for example, the weight of the U.S. nonfarm payroll series (NFP), represented by the green line in the top leftmost panel, increases on January 6, February 3, and March 9 (solid vertical lines) when the December, January and February figures are announced. Until the IP numbers are released (dotted vertical lines), nonfarm payroll has the biggest weight. With the release of the IP figures, the weight for IP (red line) increases and becomes the highest of all. However, as additional information about real activity in the United States is released, nonfarm payroll and IP weights start to decline gradually. A similar pattern can be observed in the other countries: as the more timely information becomes available, its weight jumps up and it

\footnotetext{
${ }^{18}$ Details of the average cumulative weights are reported in table B2 in the online Appendix. For comparability across countries, the table shows standardized weights so that the sum of all weights in each country is equal to 1.
} 
declines as other indicators are subsequently released. In the euro area (the top rightmost panel), unemployment tends to have the highest weight overall, but when IP numbers are released, IP weights become slightly bigger than those of the unemployment data. In the United Kingdom, IP weights are always bigger than any other weight. In Canada unemployment is consistently and by far the highest weight. Finally, in Japan, the Tankan survey has the highest weight at the beginning of the quarter when it represents the only available information for that quarter, but its weight is immediately overtaken as other information become available and, in particular, as IP numbers are released.

Turning to (ii), figure 3 shows the weights $w$ when computed on March 31, 2012 for the six months prior to that day 19 The weights in all the countries display a time decay feature. For the United States, nonfarm payroll and IP (the green and red bars) have the highest weight for the month of February based on information as of March 31, 2012. Interestingly, IP weights are more persistent than the others, suggesting that past IP information continues to be important whereas the nonfarm payroll information value is limited to the latest available month. Because no data about March are released as of March 31, all the weights are zero for the month of March. Weights are close to zero for all indicators after about six months. Of note, the time decay feature implies that an increase in the index might be due to a smaller weight given to an old negative surprise or to a new positive surprise.

The Euro Area represents an interesting case because as of March 31, 2012, flash euro-area PMI numbers for February and March are available, whereas any other real activity information refers to January. While past PMI numbers have a very small weight, the February and March PMI figures have a relatively high weight. Once more, the weights for IP are the slowest to decline, and the last available unemployment data displays the highest weight.

The United Kingdom seems to have the slowest time decay in its weights compared to the other countries. In Canada, the employment weights dominate every other weight. Japan displays the quickest time decay with weights reaching practically zero already after only four months. Unlike the other countries, unemployment does not have the highest weight.

These weights are computed based on the available information as of March 31, 2012. Of course, the pattern would be different if the weights were to be

\footnotetext{
${ }^{19}$ The idea is that $w_{j}^{i}$ represents the bars in figure 3 while $w_{c u m}^{i}$ represent the lines in figure 2
} 
computed on another day when different information was available.

\subsection{Surprise Indexes}

The news surprise indexes for the United States, the Euro area, the United Kingdom, Canada, Japan, and the aggregate of the five countries are displayed in figure 4 (solid lines) ${ }^{20}$ A positive (negative) reading of the surprise index suggests that economic releases have on balance been higher (lower) than consensus, meaning that agents were ex-post more pessimistic (optimistic) about the economy. A positive number does not mean the economy is doing well on any ordinary measure, but merely that economic forecasts were overly pessimistic. The surprise index reaches its lowest value during the global financial crisis of 2008-2009 in most countries. This suggests that, as the crisis was unfolding, agents were less pessimistic about its possible outcome and its impact on the real economy, while the actual data turned out to depict a grimmer picture of the stance of economic activity around the globe.

The euro-area surprise index dropped sharply in March 2012. As agents became more optimistic on a resolution of the European debt crisis with the bond exchange taking place in Greece, real activity indicators for 2012 that were released in March were disappointing. The January unemployment rate, released on March 1, was 10.70 percent versus an expectation of 10.40 percent. The February and March euro-area PMIs released on February 22 and March 22 were 49.70 and 48.70 respectively, versus expected values of 50.50 and 49.60 , respectively. Finally, based on data released on March 14, euro-area industrial production increased 0.2 percent from December 2011 to January 2012 versus an expectation of a 0.5 increase.

Interestingly, the U.K. index dropped sharply on January 25, 2011 when a very disappointing Q4 GDP for 2010 was released (-0.5 percent versus an expectation of +0.5 percent). Although subsequent data helped the index to move higher, it continued to be depressed until the second half of 2011. Agents reportedly attributed the slowdown to a series of temporary factors (such as bad weather, the Japanese earthquake, and the royal wedding) that were believed to be short-lived. The transitory nature of these events most probably made agents mark up their economic outlook, but, as a series of temporary factors occurred, these expectation were always disappointed.

${ }^{20}$ The indexes continue to be updated daily and are available from the author upon request. 
The Japanese surprise index dropped sharply on April 27, 2011 as the actual number for IP turned out to be a lot lower than expected following the March 2011 earthquake: IP decreased 15.30 percent between February and March versus the expectation of a 10.60 percent decrease.

On the other hand, there are also several instances where the surprise indexes are positive, especially coming out of the recession in the United States, the United Kingdom, and Canada.

More generally, the surprise indexes seem to be autocorrelated. Part of this feature comes from the fact that old surprises continue to receive a positive weight for some time after their release. Except for Canada, the surprise indexes are on average slightly negative, with a more negative value during recessions suggesting that, in the period considered, agents were on average overly optimistic about the state of the economy.

For comparison, the dotted lines in figure 4 show the Citi Economic Surprise Indexes (CESI). Although CESIs also measure economic news, they are constructed based on a different methodology. CESIs are defined as weighted historical standard deviations of data surprises (actual releases versus Bloomberg median survey) and are calculated daily in a rolling three-month window. The weights of the economic indicators are derived from relative high-frequency spot foreign exchange impacts of 1 standard deviation data surprises adjusted to include a time decay feature so as to replicate the limited memory of markets. Because the index constructed in this paper does not rely on the impact that macroeconomic surprises have on asset prices, it represents a more objective measure of deviation from consensus expectations. Although the two indexes follow very similar patterns for all the countries, they also present some differences because both the set of indicators and the weights are different. For example, the euro-area surprise index tends to lag the CESI especially during the shaded area which represents the 2008-2009 recession.

\subsection{Uncertainty Indexes}

The uncertainty indexes for the United States, the Euro area, the United Kingdom, Canada, Japan and the aggregate of the five countries are displayed in figure 5 (solid lines). These indexes measure how uncertain agents are about realized real activity conditions. A greater (smaller) reading of the uncertainty index suggests that agents have on balance been more (less) uncertain about the state of the current economy. The indexes tend to be elevated during recessions,

although there are other episodes when the indexes spike up. In the United 
States, economic uncertainty was also relatively high in 2004 and a big jump was observed at the end of 2005 and in 2012. The euro-area uncertainty index reaches its highest values just before and after the 2008-2009 recession, suggesting that agents were more uncertain about the economy as the euro-zone was entering and exiting the recession. Increased macro uncertainty characterized also the beginning of 2010, when the Greece "problem" started to emerge, and the period between the end of 2011 and the start of 2012. Uncertainty in the United Kingdom has been particularly elevated since early 2009, when compared to its value in the first part of the sample. Canada has experienced several episodes of elevated economic uncertainty, whereas in Japan, the period after the March 2011 earthquake was by far the one with the highest uncertainty regarding the state of the Japanese economy. Interestingly, higher volatility is associated with negative surprises. The correlation between the surprise index and the uncertainty index tends to be stronger when the surprise index is negative.

The dotted lines in the panels show stock market implied volatilities in the United States, Euro Area, United Kingdom, Canada, and Japan as represented by the VIX, VSTOXX, VTFSE, VIXC and VXJ. The dashed lines display the stock market realized volatilities for the respective countries. Notably, especially in the latter part of the sample, the uncertainty index and the VIX look somewhat similar, whereas the uncertainty index of the euro area differs from the VSTOXX ${ }^{21}$ The two measures (implied volatility and uncertainty index) are constructed in completely independent ways. Implied volatility, a forwardlooking measure, is computed from option prices. The uncertainty index, a historical measure, is calculated from current and past macroeconomic news surprises. The former is a wider measure that combines information about risk aversion and future stock market volatility, and to the extent that these two move with news surprises, the VIX also contains information about current and future economic uncertainty. On the other hand, the uncertainty index presented here is a clean measure of agents' uncertainty about the current state of the economy. In the analysis that follows, I will decompose the VIX into stock market uncertainty and variance risk premium, following Bakaert et al. (2013), to use the part of the VIX that is most comparable to uncertainty.

\footnotetext{
${ }^{21}$ Table B3 in the online Appendix displays the correlation between the uncertainty measure and the implied and realized volatilities for each country.
} 


\section{Applications}

In this section, I present a couple of applications for the surprise and uncertainty indexes. In the first application, the surprise index is shown to preserve the properties of the underlying macro series in affecting asset prices in replicating the regressions shown in table 2. Combining several macro series into one, the surprise index has the advantage of being potentially easier to use and very parsimonious. In light of this, Demiralp et al. (2013) make use of it as a control variable when investigating the effects of political commentaries on policy rate decisions and policy expectations in the United States and the Euro Area, and find it to be a significant determinant of policy expectations. Similarly, Brunetti et al. (2013) employ it as a control variable in studying the impact of speculation activity in the crude oil market.

In the second application, the U.S. uncertainty index is compared to other uncertainty measures commonly used in the literature. The uncertainty index has a negative impact on real-activity series. Papers like Bloom (2009), Baker et al. (2015), and Bachmann et al. (2013) have documented a similar analysis with different measures of uncertainty. I find that, in the United States over the last decade, when uncertainty is strictly related to the state of the economy as measured by real activity, it has a potentially milder impact on macro activity than when the uncertainty is related to both the macro and the financial sectors as measured by the VIX.

\subsection{Surprise Indexes and News Impact on Foreign Exchanges}

As shown in section 2, macroeconomic news announcements affect asset prices. The surprise index presented in this paper represents a nice summary measure that can be used to parsimoniously control for news announcement surprises in more general models.

Table 3 presents the results of a set of regressions where the euro $/ \$, \mathrm{GBP} / \$$, $\mathrm{CAD} / \$$, and JPY $/ \$$ exchange rate returns are regressed on the U.S. surprise index and the respective foreign surprise index, i.e. the euro $/ \$$ return is regressed on the U.S surprise index and the euro-area surprise index, the GBP $/ \$$ return is regressed on the U.S surprise index and the U.K. surprise index, etc. I cover approximately the sample period for which the surprise indexes are available (July 2003 to March 2016) ${ }^{22}$ As shown in the table, the surprise indexes tend

\footnotetext{
${ }^{22}$ For comparison with the exercise in table 2 I run the regression only on days in which
} 
to have the right sign and be significant: a positive change in the U.S. surprise index (i.e. the U.S. economy doing better than expected) appreciates the U.S. dollar versus the foreign currency, whereas a positive change in the foreign surprise index depreciates the U.S. dollar.

\subsection{Uncertainty Measures and the Business Cycle}

A "true" measure of economic uncertainty does not exist and stock market realized and implied volatilities have been commonly used as proxies for uncertainty. Bloom (2009), for example, uses the Chicago Board of Option Exchange VXO index as a proxy for uncertainty ${ }^{23}$ More recently, a growing literature has focused on finding new measures of macroeconomic uncertainty. Bachmann et al. (2013) use survey expectation data to construct time-varying business-level uncertainty. For Germany and the United States, they construct a measure of uncertainty with forecast disagreement from the IFO Business Climate Survey and the Business Outlook Survey, respectively. Baker et al. (2015) create an economic policy uncertainty (EPU) measure based on the frequency of newspaper references to economic policy uncertainty, the number and size of the federal tax code provisions set to expire in future years, and the disagreement among economic forecasters about policy relevant variables. Leduc and Liu (2012) use a measure of perceived uncertainty of consumers and businesses from the Thomson Reuters/University of Michigan Surveys of Consumers in the United States and the Confederation of British Industry (CBI) Industrial Trends Survey in the United Kingdom. Bakaert et al. (2013) decompose the VIX into variance risk premium, a measure of risk aversion, and stock market uncertainty. Jurado et al. (2015) define uncertainty as the variability in the purely unforecastable component of the future value of a variable and measure macro uncertainty as the uncertainty factors common to individual measures of uncertainty across a large number of series. Similarly to Jurado et al. (2015), my measure uses forecast errors, which, however, are not the objective and efficient forecast errors from a model. Instead they are market based forecast errors and as such my uncertainty index measures the perceived uncertainty about the state of the

there are news releases. This implies that I will have 556, 423, 443, 417, and 298 observations for the U.S., euro-area, U.K., Canadian and Japanese news, respectively.

${ }^{23}$ The VXO is equivalent to the VIX series that I use. The VIX was launched in 1993. In 2003, its formula was modified substantially. Data from the new 2003 VIX formula, also used to reconstruct historical data going back to 1990, is known as the VIX. The data associated with the original and revised VIX formulae is known as VXO. In my sub-sample VIX and VXO coincide. 
economy. Agents base decisions on their perceived uncertainty rather than an objective uncertainty that they do not observe.

Figure 6 compares the real-activity uncertainty index developed here against some of the available other measures of uncertainty for the United States. All measures are de-meaned and standardized for comparison; they are all countercyclical, rising during economic downturns. The correlation of the uncertainty index ranges from about 20 percent between with the Baker, Bloom, and Davis EPU to over 60 percent with the VIX ${ }^{24}$ The uncertainty index exceeds 1.65 standard deviations above its mean only few times but the peaks do not always correspond with the peaks of the other series suggesting that these uncertainty measures might indeed carry slightly different information.

A growing literature has also focused on analyzing the relationship between real activity and uncertainty, and the latter has been generally found to have a significant role in firms' hiring decisions (employment) and output. To estimate such effects, I estimate a bivariate VAR with log employment and each one of the uncertainty proxies from figure 6 , separately. Because of the short data set (monthly data from May 2003 to March 2016), the bivariate VAR represents a parsimonious way to model the joint dynamics between these variables. As shown in Bachmann et al. (2013), the results are robust to estimating a larger VAR similar to Bloom (2009) ${ }^{25}$ Each VAR is estimated selecting the lag length based on the Schwarz Information Criterion; employment enters in log levels, while uncertainty measures in levels.

Figure 7 shows the recursive impulse responses of employment to a onestandard-deviation uncertainty shock as measured by the different proxies, where uncertainty is ordered first. The shaded region is the $+/$ - one standard error confidence interval for the real-activity uncertainty shock. Employment decreases after an uncertainty shock, no matter which uncertainty proxy is used. However, how quickly and how deeply varies across measures, with shocks to the VIX or the Bakaert et al. (2013) stock market uncertainty being the most quick to materialize and the ones with the deepest trough. Shocks to the macroeconomic uncertainty index, to the Baker et al. (2015) EPU measure and the

\footnotetext{
${ }^{24}$ The smallest correlation is between Bachmann, Elstner, and Sims and Baker, Bloom, and Davis measures (about 10 percent). The highest correlations are between the VIX and the Bakaert uncertainty/variance risk premium decomposition of the VIX (about 85-90 percent), followed by the correlation between the VIX between Baker, Bloom, and Davis EPU measure (about 70 percent).

${ }^{25}$ Given the short dataset, I only estimate the bivariate VAR.
} 
Bachmann et al. (2013) dispersion measure elicit a progressively lower impact on employment over this period. This result suggests that when uncertainty is strictly related to real activity, it has potentially milder impact on economic activity. Just flipping the argument, when uncertainty is more generally related to economic as well as financial conditions as measured by the VIX or the Bakaert et al. (2013) measure of stock market uncertainty, its impact on real-activity variables appears to be stronger ${ }^{26}$ This finding supports recent work by Caldara et al. (2013) which finds that the financial channel is key in the transmission of uncertainty shocks. Although I do not explicitly introduce a financial channel, using the real-activity uncertainty index, the VIX and the Bakaert stock market uncertainty measure allows me to distinguish between purely macro versus the more general macro and financial uncertainty. Interestingly, the variance risk premium (not shown) does not seem to play a very important role ${ }^{27}$ An analysis of the fraction of the VAR forecast error variance of employment that is attributable to innovations in each of the uncertainty series over different forecast horizons confirms the results: the VIX and the Bakaert stock market uncertainty decomposition explain about 2-3 times the share of the forecast error of employment compared to the real-activity uncertainty index.

For robustness, some alternative specifications are considered. The result just described holds true with other measures of real activity, such as industrial production or unemployment rate. Although a similar comparison is not shown for the other countries, the negative impact of an uncertainty shock on employment is generally significant across countries. As a robustness check, I estimate generalized impulse responses from Pesaran and Shin (1998) which do not depend on the ordering of the variables and the results remain quite consistent across uncertainty proxies and variables.

\section{Summary and Concluding Remarks}

The goal of this paper is to construct measures of (i) real-time economic news and their deviation from consensus expectations and (ii) real-time uncertainty about the state of the economy. I view this paper as a "complement"

\footnotetext{
${ }^{26}$ Figure A1 shows the confidence intervals for the real-activity uncertainty index and the VIX.

${ }^{27}$ The variance risk premium, computed as in Bakaert et al. (2013), elicits an impulse response to employment similar to that of Baker et al. (2015) EPU.
} 
to the Aruoba et al. (2009) business condition index updated on a daily basis by the Federal Reserve Bank of Philadelphia. While the ADS index is a real time measurement of the state of the economy, the surprise index presented in this paper measures agents' optimism or pessimism about the economy by combining macroeconomic news surprises, and the uncertainty index measures agents' uncertainty about the current state of the economy. This paper is also a "complement" to other papers that develop uncertainty measures in that it only measures perceived uncertainty about the state of the economy and as such is mostly linked to Bachmann et al. (2013).

I look forward to a variety of variations and extensions of this basic theme, including but not limited to:

- constructing indexes for nominal variables to gauge optimism/pessimism about inflation stance

- incorporating additional indicators and surprises for each country to construct a summary measure of real and nominal variables

- extending the framework to include U.S. macro surprises into foreign economies frameworks to exploit the correlation/causation across business cycles

- including vintages of data so that the indexes change not only when new information is released but also when past information is revised

- expanding the dataset to construct indexes with a longer history

- analyzing in more depth the impact of different types of uncertainty.

\section{References}

Andersen, T. G., Bollerslev, T., Diebold, F. X., Vega, C., 2003. Micro effects of macro announcements: Real-time price discovery in foreign exchange. American Economic Review 93, 38-62.

Andersen, T. G., Bollerslev, T., Diebold, F. X., Vega, C., 2007. Real-time price discovery in stock. Journal of International Economics 73, 251-27.

Andreou, E., Kourtellos, A., Ghysels, E., 2011. Forecasting with mixedfrequency data. Oxford Handbook of Economic Forecasting, Chapter 8. 
Aruoba, B. S., Diebold, F. X., Scotti, C., 2009. Real-time measurement of business conditions. Journal of Business and Economic Statistics 27, 417-42.

Bachmann, R., Elstner, S., Sims, E., 2013. Uncertainty and economic activity: Evidence from business survey data. American Economic Journal:Macroeconomics 5 (2), 217-24.

Bakaert, G., Hoerova, M., Lo Duca, M., 2013. Risk, uncertainty and monetary policy. Journal of Monetary Economics 60, 771-788.

Baker, S. R., Bloom, N., Davis, S. J., 2015. Measuring economic policy uncertainty, working Paper.

Banbura, M., Giannone, D., Reichlin, L., 2010. Nowcasting. In: Clements, M., Hendry, D. (Eds.), Handbook on Economic Forecasting. Oxford.

Banbura, M., Modugno, M., 2014. Maximum likelihood estimation of large factor model on dataset with arbitrary pattern of missing data. Internationa Journal of Forecasting 29, 133-16.

Banbura, M., Runstler, G., 2010. A look into the factor model black box: Publication lags and the role of hard and soft data in forecasting gdp. International Journal of Forecasting 27, 333-346.

Bloom, N., 2009. The impact of uncertainty shocks. Econometrica 77, 623-68.

Brunetti, C., Buyuksahin, B., Harris, J., 2013. Do institutional traders predict bull and bear markets?, working Paper.

Caldara, D., Fuentes-Albero, C., Gilchrist, S., Zakrajsek, E., 2013. On the identification of financial and uncertainty shocks, mimeo.

Camacho, M., Perez-Quiroz, G., 2009. Introducing the euro-sting: Short-term indicator of euro area growth. Journal of Applied Econometrics 25, 663-69.

Constable, S., Wright, R. E., 2011. The WSJ Guide to the 50 Economic Indicators That Really Matter: From Big Macs to Zombie Banks, the Indicators Smart Investors Watch to Beat the Market. Harper Collins.

Croushore, D., Stark, T., 2001. A real-time dataset for macroeconomists. Journal of Econometrics 105, 111-13. 
Demiralp, S., King, S., Scotti, C., 2013. Does anyone listen when politicians talk? the impact of political commentaries on policy rate decisions and expectations, mimeo.

Doz, C., Giannone, D., Reichlin, L., 2011. A two-step estimator for large approximate dynamic factor models based on kalman filtering. Journal of Econometrics 64 (1), 188-20.

Doz, C., Giannone, D., Reichlin, L., 2012. A quasi maximum likelihood approach for large approximate dynamic factor models. Review of Economics and Statistics 94 (4), 1014-102.

Faust, J., Rogers, J. H., Wright, J., 2005. News and noise in g-7 gdpannouncements. Journal of Money 37 (3), 403-41.

Fostel, A., Geanakoplos, J., 2012. Why does bad news increase volatility and decrease leverage? Journal of Economic Theory 147 (2), 501-52.

Giannone, D., Reichlin, L., Small, D., 2008. Nowcasting: The real-time informational content of macroeconomic data. Journal of Monetary Economics 55 (4), $665-67$.

Gilbert, T., Scotti, C., Strasser, G., Vega, C., 2012. Why do certain macroeconomic news announcements have a big impact on asset prices?, mimeo.

Jurado, K., Ludvigson, S., Ng, S., 2015. Measuring uncertainty. American Economic Review 105 (3), 1177-1216.

Koopman, S. J., Harvey, A., 2003. Computing observation weights for signal extraction and filtering. Journal of Economic Dynamics (27), 1317-1333.

Leduc, S., Liu, Z., 2012. Uncertainty shocks are aggregate demand shocks, fRBSF Working Paper.

Mincer, J., Zarnowitz, V., 1969. The evaluation of economic forecasts. In: Mincer, J. (Ed.), Economic Forecast and Expectations. New York: National Bureau of Economic Research, pp. 81-111.

Pesaran, H., Shin, Y., 1998. Generalized impulse response analysis in linear multivariate models. Economics Letters 58 (1), 17-29. 
Table 1: Forecast efficiency regression results (July 2003 - March 2016)

\begin{tabular}{|c|c|c|c|c|c|}
\hline Country & Series Name & $\alpha$ & $\beta$ & $\mathbf{F}$ & pvalue \\
\hline \multirow[t]{6}{*}{ United States } & GDP & -0.05 & -0.02 & 0.65 & 0.53 \\
\hline & IP & $-0.09^{* * *}$ & $0.27^{* * *}$ & 12.55 & 0.00 \\
\hline & Employment & $-12.70^{* *}$ & -0.01 & 2.87 & 0.06 \\
\hline & Retail Sales & -0.05 & $0.18^{* * *}$ & 5.15 & 0.01 \\
\hline & ISM & 1.12 & -0.02 & 0.67 & 0.51 \\
\hline & Personal Income & $0.04^{*}$ & $-0.11^{* * *}$ & 4.17 & 0.02 \\
\hline \multirow[t]{5}{*}{ Euro area } & GDP & -0.02 & $0.11^{* * *}$ & 3.31 & 0.04 \\
\hline & IP & $-0.08^{*}$ & $-0.11^{* *}$ & 3.81 & 0.02 \\
\hline & Unemployment & $0.10^{* *}$ & $-0.01^{* *}$ & 3.13 & 0.05 \\
\hline & Retail Sales & -0.07 & $-0.13^{*}$ & 1.93 & 0.15 \\
\hline & PMI & 1.03 & -0.02 & 0.42 & 0.66 \\
\hline \multirow[t]{5}{*}{ United Kingdom } & GDP & $-0.14^{* * *}$ & $0.26^{* * *}$ & 6.58 & 0.00 \\
\hline & IP & $-0.21^{* * *}$ & $-0.01^{* * *}$ & 9.22 & 0.00 \\
\hline & Unemployment & $0.05^{* * *}$ & $-0.02^{* * *}$ & 7.73 & 0.00 \\
\hline & Retail Sales & $0.20^{* * *}$ & $0.11^{* * *}$ & 5.88 & 0.00 \\
\hline & PMI & $3.28^{*}$ & $-0.06^{* *}$ & 1.93 & 0.15 \\
\hline \multirow[t]{5}{*}{ Canada } & GDP & 0.06 & -0.01 & 0.23 & 0.80 \\
\hline & IP & $-0.06^{* * *}$ & $0.06^{* * *}$ & 7.00 & 0.00 \\
\hline & Employment & 5.17 & $0.12^{* * *}$ & 2.98 & 0.05 \\
\hline & Retail Sales & -0.07 & $0.35^{* * *}$ & 5.78 & 0.00 \\
\hline & Ivey Survey & $19.95^{* * *}$ & $-0.34^{* * *}$ & 7.23 & 0.00 \\
\hline \multirow[t]{5}{*}{ Japan } & GDP & 0.01 & -0.05 & 0.25 & 0.78 \\
\hline & IP & $-0.42^{* * *}$ & $0.04^{* * *}$ & 10.66 & 0.00 \\
\hline & Unemployment & $0.17^{*}$ & $-0.05^{* * *}$ & 4.57 & 0.01 \\
\hline & Retail Sales & 0.04 & $0.21^{* * *}$ & 6.02 & 0.00 \\
\hline & Tankan & 0.16 & 0.01 & 0.27 & 0.76 \\
\hline
\end{tabular}

* 10 percent significance, ${ }^{* *} 5$ percent significance, and ${ }^{* * *} 1$ percent significance. 
Table 2: Results of univariate regressions in which exchange rate returns are regressed on each individual macroeconomic news announcement surprise (July 2003 - March 2016)

\begin{tabular}{|c|c|c|c|c|c|c|c|c|}
\hline & \multicolumn{2}{|c|}{ Euro $/ \$$} & \multicolumn{2}{|c|}{ GBP /\$ } & \multicolumn{2}{|c|}{$\mathrm{CAD} / \$$} & \multicolumn{2}{|c|}{ JPY /\$ } \\
\hline & Beta & R2 & Beta & $\mathbf{R} 2$ & Beta & $\mathbf{R 2}$ & Beta & R2 \\
\hline \multicolumn{9}{|l|}{ US } \\
\hline IP & 0.029 & 0.003 & 0.021 & 0.001 & $0.043^{* *}$ & 0.005 & -0.034 & 0.003 \\
\hline Employment & $0.271^{* * *}$ & 0.125 & $0.214^{* * *}$ & 0.130 & 0.002 & 0.000 & $0.342^{* * *}$ & 0.214 \\
\hline Retail sales & 0.063 & 0.013 & $0.100^{* * *}$ & 0.030 & -0.062 & 0.010 & $0.198^{* * *}$ & 0.099 \\
\hline Personal income & 0.009 & 0.000 & -0.040 & 0.004 & 0.020 & 0.001 & -0.038 & 0.004 \\
\hline PMI & 0.050 & 0.006 & 0.035 & 0.001 & -0.013 & 0.000 & $0.169^{* * *}$ & 0.067 \\
\hline GDP & $0.219^{* * *}$ & 0.097 & 0.017 & 0.000 & $0.084^{* * *}$ & 0.011 & 0.059 & 0.005 \\
\hline \multicolumn{9}{|l|}{ Foreign } \\
\hline IP & $-0.066^{* * *}$ & 0.023 & $-0.147^{* * *}$ & 0.059 & -0.028 & 0.005 & 0.077 & 0.023 \\
\hline Empl/unempl & 0.064 & 0.066 & -0.039 & 0.006 & $-0.252^{* * *}$ & -0.125 & 0.009 & 0.001 \\
\hline Retail sales & -0.106 & 0.023 & $-0.148^{* * *}$ & 0.069 & -0.013 & 0.071 & -0.013 & 0.004 \\
\hline PMI/Ivey/Tankan & 0.005 & 0.000 & $-0.238^{* * *}$ & 0.110 & -0.064 & 0.006 & 0.020 & 0.001 \\
\hline GDP & $-0.113^{* *}$ & 0.038 & $-0.371^{* * *}$ & 0.300 & -0.090 & 0.025 & -0.005 & 0.000 \\
\hline
\end{tabular}

* 10 percent, ${ }^{* *} 5$ percent, and ${ }^{* * *} 1$ percent significance with Newey-West standard errors.

Table 3: Results of univariate regressions in which exchange rate returns are regressed on the change in the surprise index (July 2003 - March 2016)

\begin{tabular}{|c|c|c|c|c|c|c|c|c|}
\hline & \multicolumn{2}{|c|}{ Euro $/ \$$} & \multicolumn{2}{|c|}{ GBP $/ \$$} & \multicolumn{2}{|c|}{$\mathrm{CAD} / \$$} & \multicolumn{2}{|c|}{$\mathbf{J P Y} / \$$} \\
\hline & $\beta$ & $\mathbf{R}^{2}$ & $\beta$ & $\mathbf{R}^{2}$ & $\beta$ & $\mathbf{R}^{2}$ & $\beta$ & $\mathbf{R}^{2}$ \\
\hline US surprise index & $0.418^{* * *}$ & 0.032 & $0.303^{* * *}$ & 0.019 & -0.061 & 0.000 & $0.482^{* * *}$ & 0.037 \\
\hline Foreign surprise index & $-0.358^{* * *}$ & 0.016 & -0.424 & 0.005 & $-0.830^{* * *}$ & 0.048 & 0.114 & 0.000 \\
\hline
\end{tabular}

* 10 percent, ${ }^{* *} 5$ percent, and $* * * 1$ percent significance with Newey-West standard errors. 
Figure 1: Real Activity Indexes (factors) for the United States, Euro Area, United Kingdom, Canada, Japan, and aggregate of the five countries, as of March 31, 2016. The average value of each index is zero by construction. A value of zero is interpreted as average economic activity for that country, whereas progressively bigger (more negative) positive values indicate progressively better-than-average (worse-than-average) conditions.
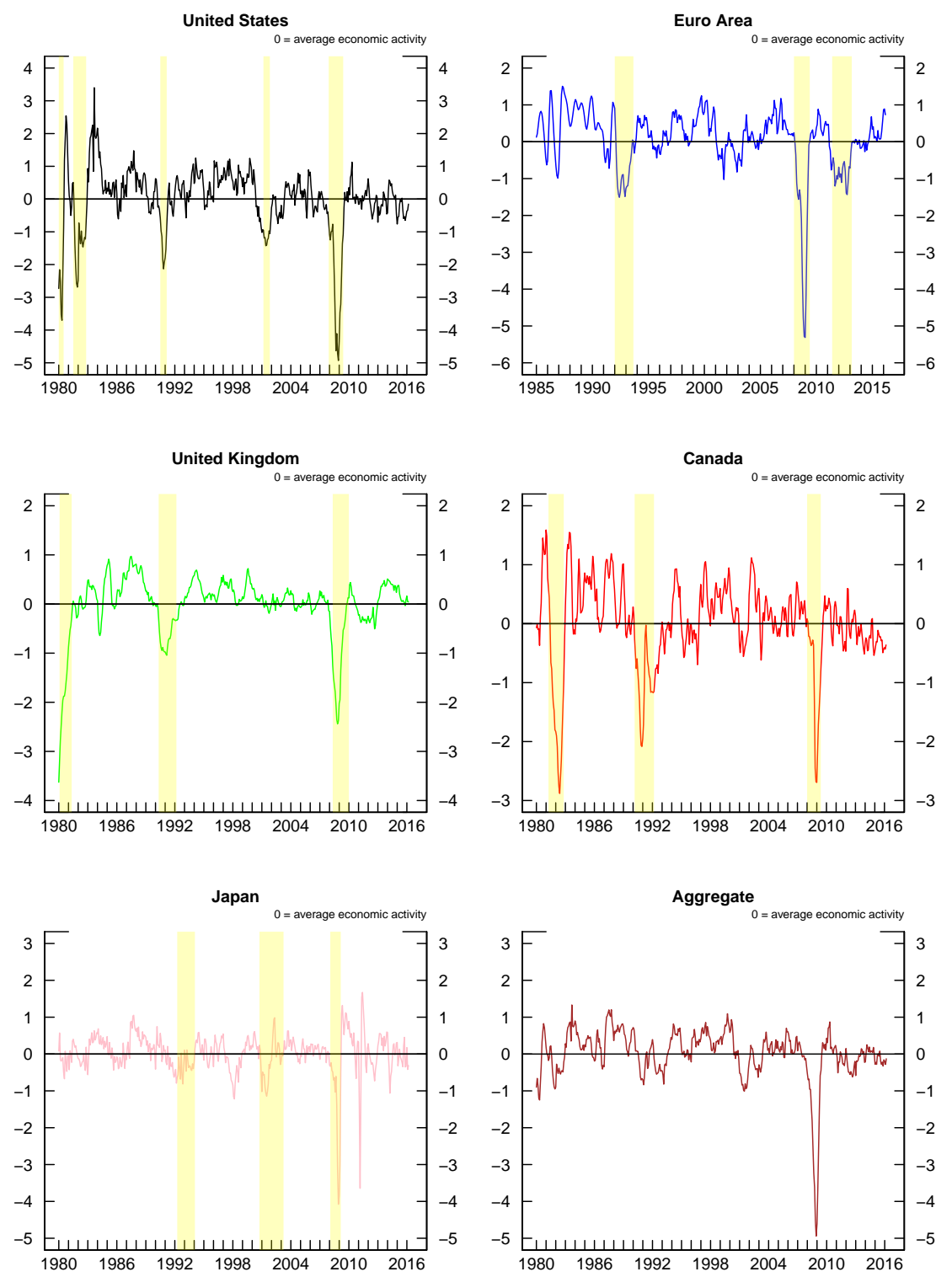
Figure 2: Average cumulative weights for the United States, Euro Area, United Kingdom, Canada, and Japan over the first quarter of 2012.

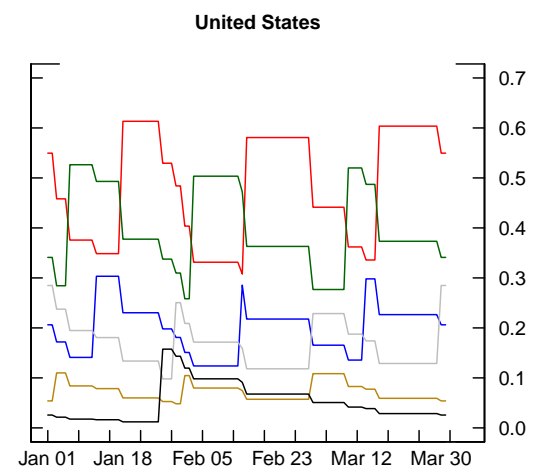

United Kingdom

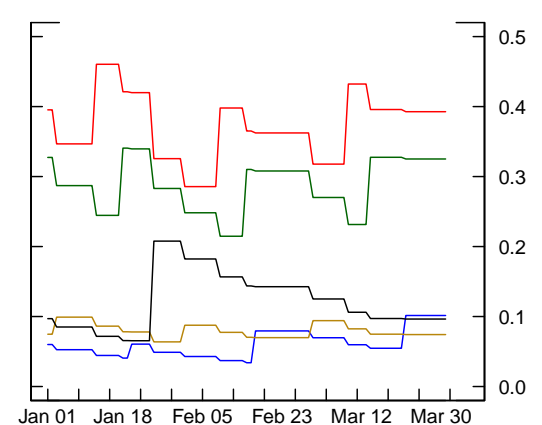

Japan

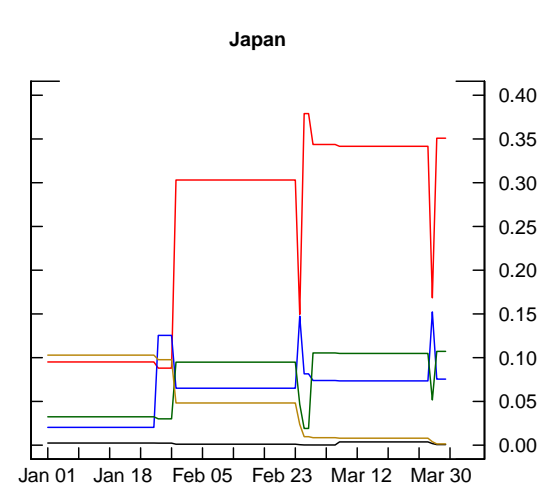

Euro Area

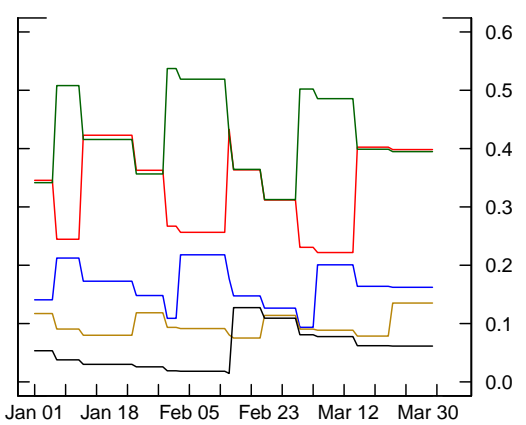

Canada

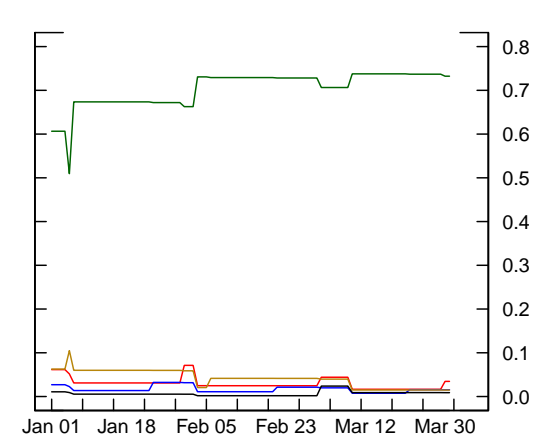

$\begin{array}{llllll}\text { Jan } 01 & \text { Jan } 18 & \text { Feb } 05 & \text { Feb } 23 & \text { Mar } 12 & \text { Mar } 30\end{array}$

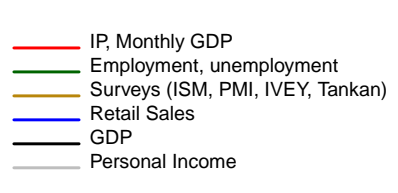


Figure 3: Time series of weights for each indicator over the 6-month period October 2011March 2012, based on the information available as of March 31, 2012.
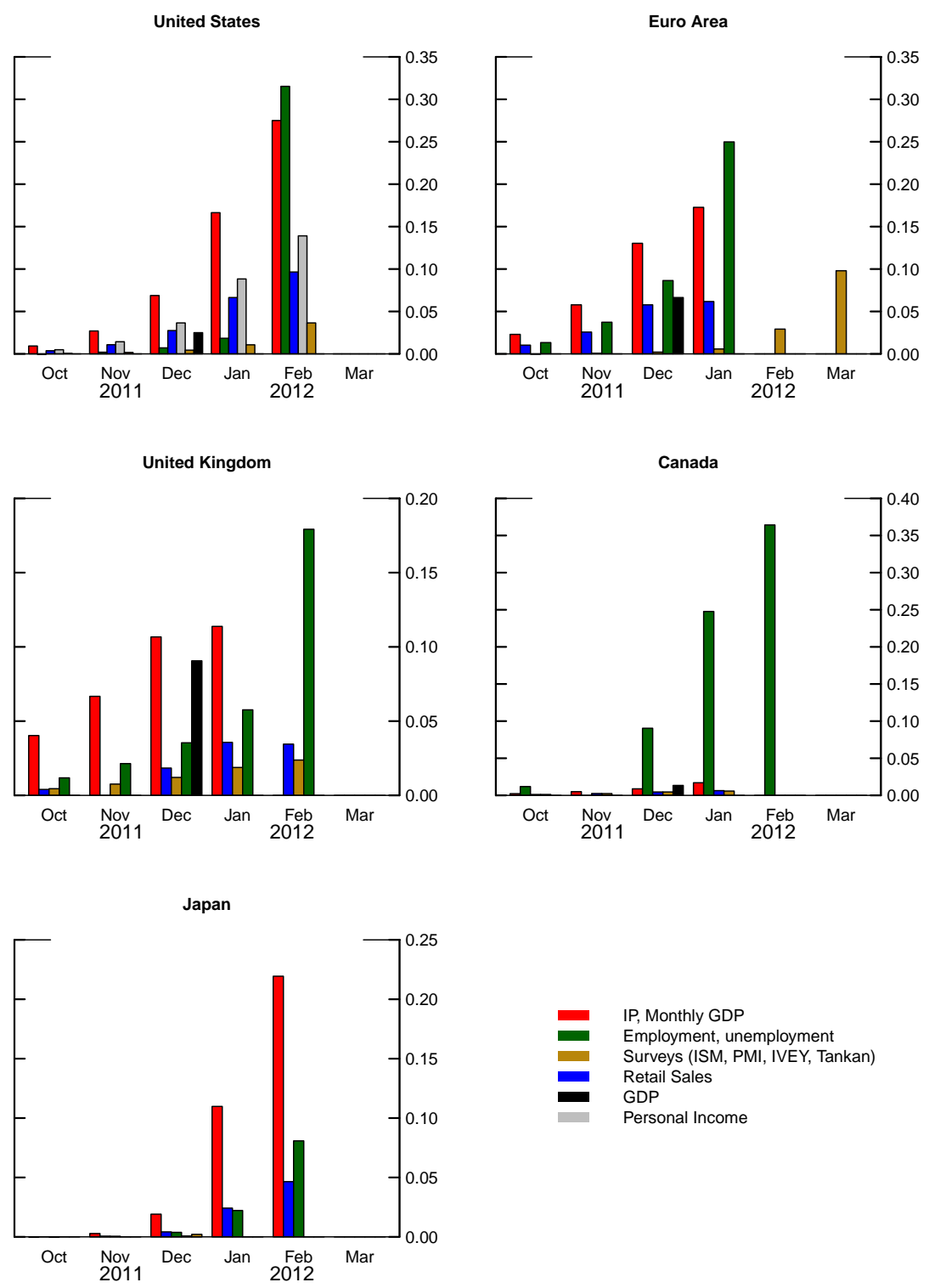

$$
\begin{aligned}
& \text { IP, Monthly GDP } \\
& \text { Employment, unemployment } \\
& \text { Surveys (ISM, PMI, IVEY, Tankan) } \\
& \text { Retail Sales } \\
& \text { GDP } \\
& \text { Personal Income }
\end{aligned}
$$


Figure 4: The solid lines show the surprise indexes for the United States, Euro Area, United Kingdom, Canada, Japan, and the aggregate of the five countries, as of March 31, 2016. The dotted lines show the Citigroup Economic Surprise Indexes for the corresponding country (left axis). A positive (negative) reading of the surprise index suggests that economic releases have on balance been higher (lower) than consensus, meaning that agents were ex-post more pessimistic (optimistic) about the economy.
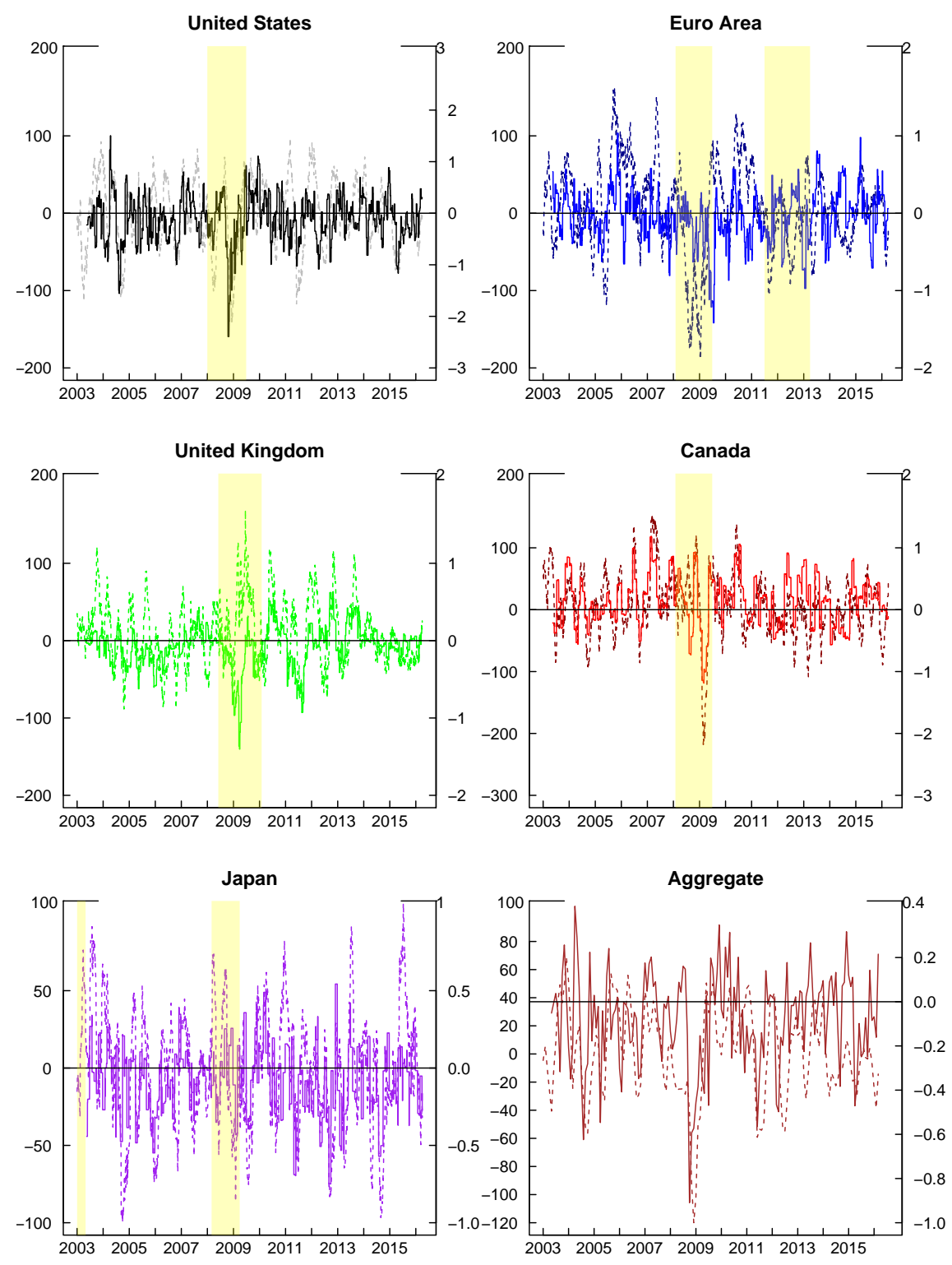
Figure 5: The solid lines show the uncertainty indexes for the United States, Euro Area, United Kingdom, Canada, Japan, and the aggregate of the five countries, as of March 31, 2016. The dotted and dashed lines show stock market implied and realized volatilities respectively (left axis).
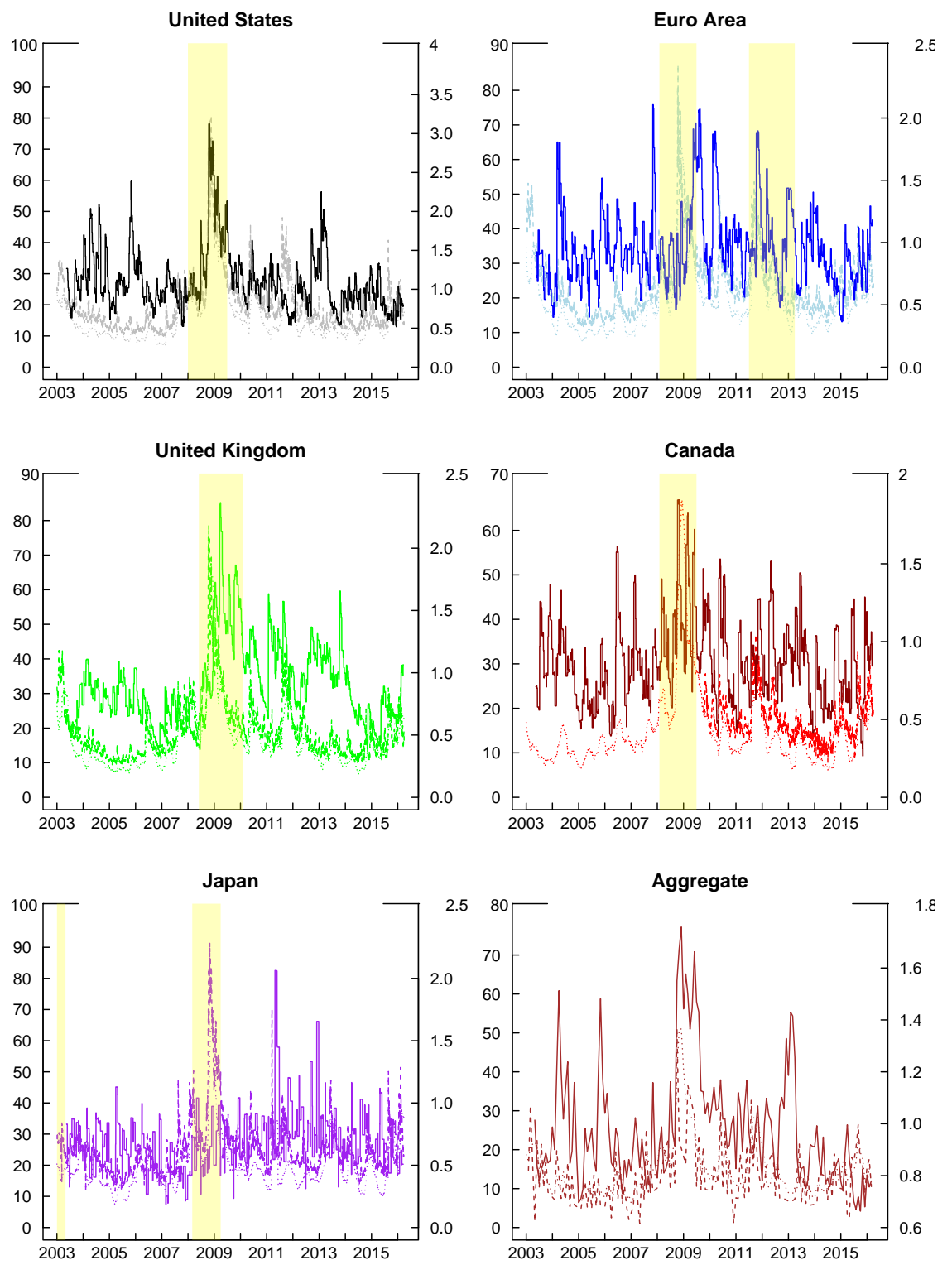
Figure 6: The solid line represents the uncertainty index which is compared against other common proxies for uncertainty, namely Bakaert et al. (2013) stock market uncertainty, Baker et al. (2015) economic policy uncertainty index, Bachmann et al. (2013) dispersion measure and the VIX. All series are demeaned and standardized. The horizontal line represents the 1.65 standard deviation limit.

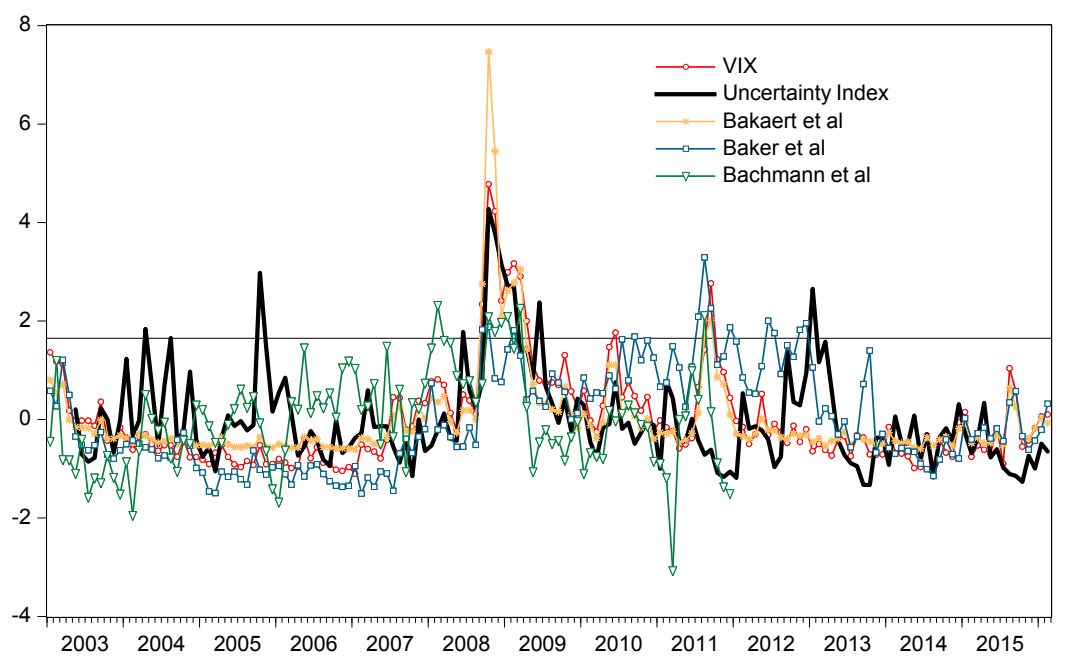


Figure 7: Employment response to a 1 standard deviation shock in the different uncertainty proxies, namely the uncertainty index, the Bakaert et al. (2013) stock market uncertainty, Baker et al. (2015) economic policy uncertainty index, Bachmann et al. (2013) dispersion measure and the VIX.

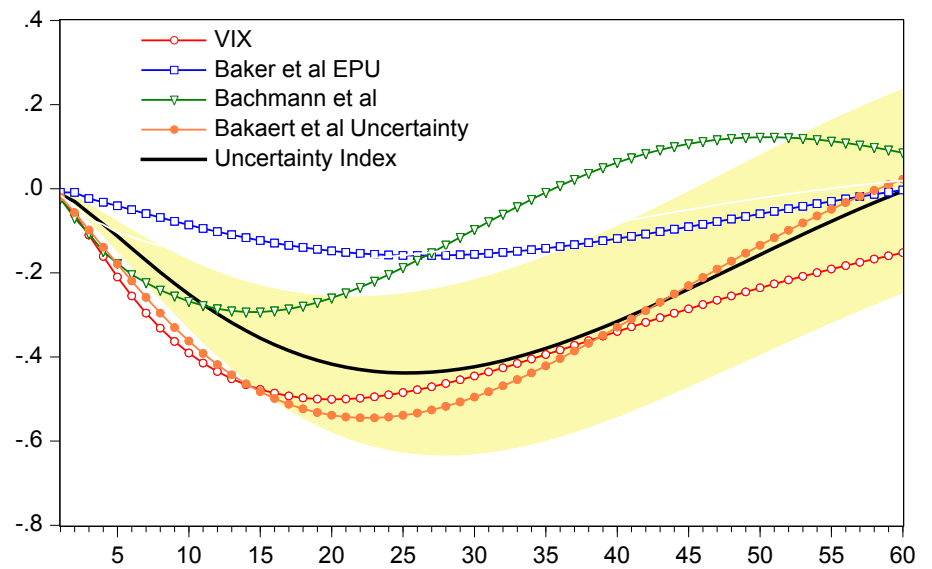




\section{Online Material - Appendix A: The Dynamic Factor Model}

I model the unobserved factor as a VAR process of order $p$ :

$$
\begin{aligned}
x_{t+1} & =\Lambda x_{t}+\eta_{t}, \\
\eta_{t} & \sim \text { i.i.d.N }\left(0, \sigma_{\eta}\right) .
\end{aligned}
$$

The model includes both monthly and quarterly variables. The monthly variables $y_{t}^{M}$ follow a single factor model representation of the type:

$$
\begin{aligned}
y_{t}^{M} & =\mu^{M}+Z^{M} x_{t}+\varepsilon_{t}^{M} \\
\varepsilon_{t}^{M} & =\alpha \varepsilon_{t-1}^{M}+e_{t}^{M}
\end{aligned}
$$

where $x_{t}$ represents the underlying real activity factor, $\varepsilon_{t}$ is a vector of idiosyncratic components, and $Z^{M}$ represent the factor loadings for the monthly variables. $\varepsilon_{t}$ follows an $A R(1)$ process, as shown in equation (.4), and $e_{t}^{M} \sim$ i.i.d.N $\left(0, \Sigma_{e}^{M}\right)$.

The quarterly variables $y_{t}^{Q}$ follow a similar factor model representation:

$$
\begin{aligned}
y_{t}^{Q} & =\mu^{Q}+Z^{Q} x_{t}+\varepsilon_{t}^{Q} \\
\varepsilon_{t}^{Q} & =\rho \varepsilon_{t-1}^{Q}+e_{t}^{Q}
\end{aligned}
$$

with $e_{t}^{Q} \sim$ i.i.d.N $\left(0, \Sigma_{e}^{Q}\right)$. Quarterly variables in the model are GDPs for all countries and the Japanese Tankan survey. I follow Mariano and Murasawa (2003) in the way I incorporate quarterly GDP into the monthly factor model. I define $Y_{t}^{Q}=100 \log (G D P)$, then

$$
y_{t}^{Q}=\left\{\begin{array}{cl}
Y_{t}^{Q}-Y_{t-3}^{Q} & \text { if } t=3,6,9,12 \\
N A & \text { otherwise }
\end{array}\right.
$$

and using the Mariano and Murasawa (2003) approximation I get that for $t=3,6,9,12$

$Y_{t}^{Q}-Y_{t-3}^{Q} \approx\left(Y_{t}^{M}+Y_{t-1}^{M}+Y_{t-2}^{M}\right)-\left(Y_{t-3}^{M}+Y_{t-4}^{M}+Y_{t-5}^{M}\right)=y_{t}+2 y_{t-1}+3 y_{t-2}+2 y_{t-3}+y_{t-4}$ 
Based on this I can link the quarterly variables to the monthly factor as

$$
\begin{aligned}
y_{t}^{Q}= & \mu^{Q}+Z_{t}^{Q} x_{t}+2 Z_{t}^{Q} x_{t-1}+3 Z_{t}^{Q} x_{t-2}+2 Z_{t}^{Q} x_{t-3}+Z_{t}^{Q} x_{t-4} \\
& +\varepsilon_{t}^{Q}+2 \varepsilon_{t-1}^{Q}+3 \varepsilon_{t-2}^{Q}+2 \varepsilon_{t-3}^{Q}+\varepsilon_{t-4}^{Q}
\end{aligned}
$$

A similar treatment can be applied to any other quarterly series in the dataset 1

Stacking monthly and quarterly variables, this model can be easily cast in a state space representation: ${ }^{2}$

$$
\begin{aligned}
y_{t} & =\mu+Z \alpha_{t} \\
\alpha_{t} & =T \alpha_{t-1}+u_{t}, \quad
\end{aligned}
$$

where $y_{t}=\left(y_{t}^{M}, y_{t}^{Q}\right)^{\prime}, \mu=\left(\mu^{M}, \mu^{Q}\right)^{\prime}$ and the state vector includes both the common factor and the idiosyncratic components:

$$
\alpha_{t}=\left(x_{t}, x_{t-1}, x_{t-2}, x_{t-3}, x_{t-4}, \varepsilon_{t}^{M}, \varepsilon_{t}^{Q}, \varepsilon_{t-1}^{Q}, \varepsilon_{t-2}^{Q}, \varepsilon_{t-3}^{Q}, \varepsilon_{t-4}^{Q}\right)^{\prime}
$$

We define the total number of indicators as $n^{M Q}$. Of course, the model could be extended to a multiple factor model.

\section{Online Material - Appendix B: The State Space Representation}

We report below the details of the state space representation as specified by equations .10 and .11 when the only quarterly variable is GDP:

\footnotetext{
${ }^{1}$ The other quarterly series in the dataset is the Japanese Tankan survey. Because it is an index, I do not compute the $\log$ difference (growth rate) as for GDP. By defining $Y_{t}^{Q}=$ Tankann $_{t}$ and $y_{t}^{Q}=Y_{t}^{Q}-Y_{t-3}^{Q}=$ Tankann $_{t}-$ Tankann $_{t-3}$, the same argument goes through and equation .8 holds exactly.

${ }^{2}$ Details about the state space representation can be found in appendix B.
} 
$\underbrace{\left[\begin{array}{c}y_{t}^{M} \\ y_{t}^{Q}\end{array}\right]}_{y_{t}}=\underbrace{\left[\begin{array}{c}\mu^{M} \\ \mu^{Q}\end{array}\right]+\left[\begin{array}{ccccccccccc}Z^{M} & 0 & 0 & 0 & 0 & I_{n^{M}} & 0 & 0 & 0 & 0 & 0 \\ Z^{Q} & 2 Z^{Q} & 3 Z^{Q} & 2 Z^{Q} & Z^{Q} & 0 & 1 & 2 & 3 & 2 & 1\end{array}\right]}_{Z} \underbrace{\left[\begin{array}{c}x_{t} \\ x_{t-1} \\ x_{t-2} \\ x_{t-3} \\ x_{t-4} \\ \varepsilon_{t}^{M} \\ \varepsilon_{t}^{Q} \\ \varepsilon_{t-1}^{Q} \\ \varepsilon_{t-2}^{Q} \\ \varepsilon_{t-3}^{Q} \\ \varepsilon_{t-4}^{Q}\end{array}\right]}_{\alpha_{t}}$ $\left[\begin{array}{c}x_{t} \\ x_{t-1} \\ x_{t-2} \\ x_{t-3} \\ x_{t-4} \\ \varepsilon_{t}^{M} \\ \varepsilon_{t}^{Q} \\ \varepsilon_{t-1}^{Q} \\ \varepsilon_{t-2}^{Q} \\ \varepsilon_{t-3}^{Q} \\ \varepsilon_{t-4}^{Q}\end{array}\right]=\underbrace{\left[\begin{array}{ccccccccccc}\Lambda & 0 & 0 & 0 & 0 & 0 & 0 & 0 & 0 & 0 & 0 \\ 1 & 0 & 0 & 0 & 0 & 0 & 0 & 0 & 0 & 0 & 0 \\ 0 & 1 & 0 & 0 & 0 & 0 & 0 & 0 & 0 & 0 & 0 \\ 0 & 0 & 1 & 0 & 0 & 0 & 0 & 0 & 0 & 0 & 0 \\ 0 & 0 & 0 & 1 & 0 & 0 & 0 & 0 & 0 & 0 & 0 \\ 0 & 0 & 0 & 0 & 0 & \operatorname{diag}\left(\alpha_{1}, \ldots, \alpha_{n^{M}}\right) & 0 & 0 & 0 & 0 & 0 \\ 0 & 0 & 0 & 0 & 0 & 0 & \alpha_{Q} & 0 & 0 & 0 & 0 \\ 0 & 0 & 0 & 0 & 0 & 0 & 1 & 0 & 0 & 0 & 0 \\ 0 & 0 & 0 & 0 & 0 & 0 & 0 & 1 & 0 & 0 & 0 \\ 0 & 0 & 0 & 0 & 0 & 0 & 0 & 0 & 1 & 0 & 0 \\ 0 & 0 & 0 & 0 & 0 & 0 & 0 & 0 & 0 & 1 & 0\end{array}\right]}_{T}\left[\begin{array}{c}x_{t-1} \\ x_{t-2} \\ x_{t-3} \\ x_{t-4} \\ x_{t-5} \\ \varepsilon_{t-1}^{M} \\ \varepsilon_{t-1}^{Q} \\ \varepsilon_{t-2}^{Q} \\ \varepsilon_{t-3}^{Q} \\ \varepsilon_{t-4}^{Q} \\ \varepsilon_{t-5}^{Q}\end{array}\right]+\underbrace{\left[\begin{array}{c}\eta_{t} \\ 0 \\ 0 \\ 0 \\ 0 \\ e_{t}^{M} \\ e_{t}^{Q} \\ 0 \\ 0 \\ 0 \\ 0\end{array}\right]}_{u_{t}}$

with $n^{M}$ and $n^{Q}$ representing the number of monthly and quarterly variables, $\varepsilon_{t}^{M}=\left(\varepsilon_{t}^{1^{M}}, \ldots, \varepsilon_{t}^{n^{M}}\right)^{\prime}, e_{t}^{M}=\left(e_{t}^{1^{M}}, \ldots, e_{t}^{n^{M}}\right)^{\prime}, \varepsilon_{t}^{Q}=\left(\varepsilon_{t}^{1^{Q}}, \ldots, \varepsilon_{t}^{n^{Q}}\right)^{\prime}$ and $e_{t}^{Q}=$ $\left(e_{t}^{1^{Q}}, \ldots, e_{t}^{n^{Q}}\right)^{\prime}$. Because we are considering the case of only one quarterly variable, $\varepsilon_{t}^{Q}=\left(\varepsilon_{t}^{1^{Q}}\right)$ and $e_{t}^{Q}=\left(e_{t}^{1^{Q}}\right)$. Also $Z^{M}=\left(Z^{1^{M}}, \ldots, Z^{n^{M}}\right)$ and 


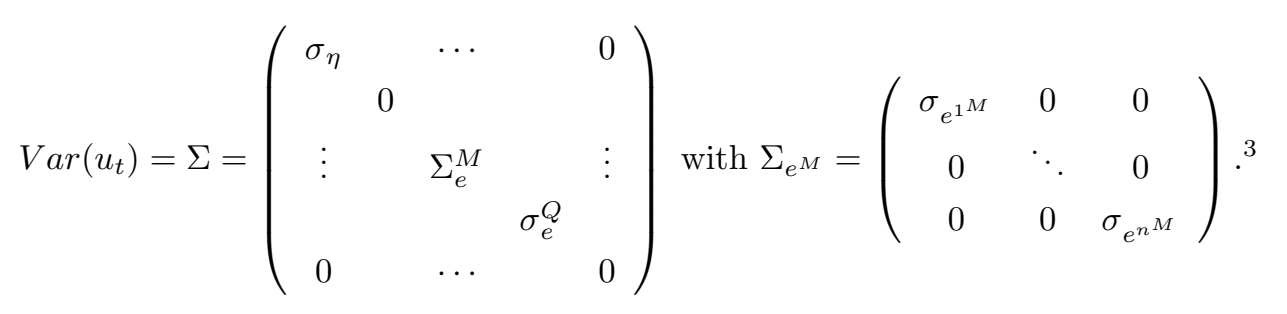

The parameters to be estimated are $\theta=\left\{\mu^{M}, \mu^{Q}, Z^{M}, Z^{Q}, \Lambda, \alpha_{1}, \ldots, \alpha_{n^{M}}, \alpha_{Q}, \sigma_{\eta}, \sigma_{e^{1}}^{M}, \ldots, \sigma_{e^{n^{M}}}^{M}, \sigma_{e}^{Q}\right\}$. ${ }^{3}$ We use the notation $\Sigma$ to indicate a variance-covariance matrix and $\sigma$ to indicate its
elements. 


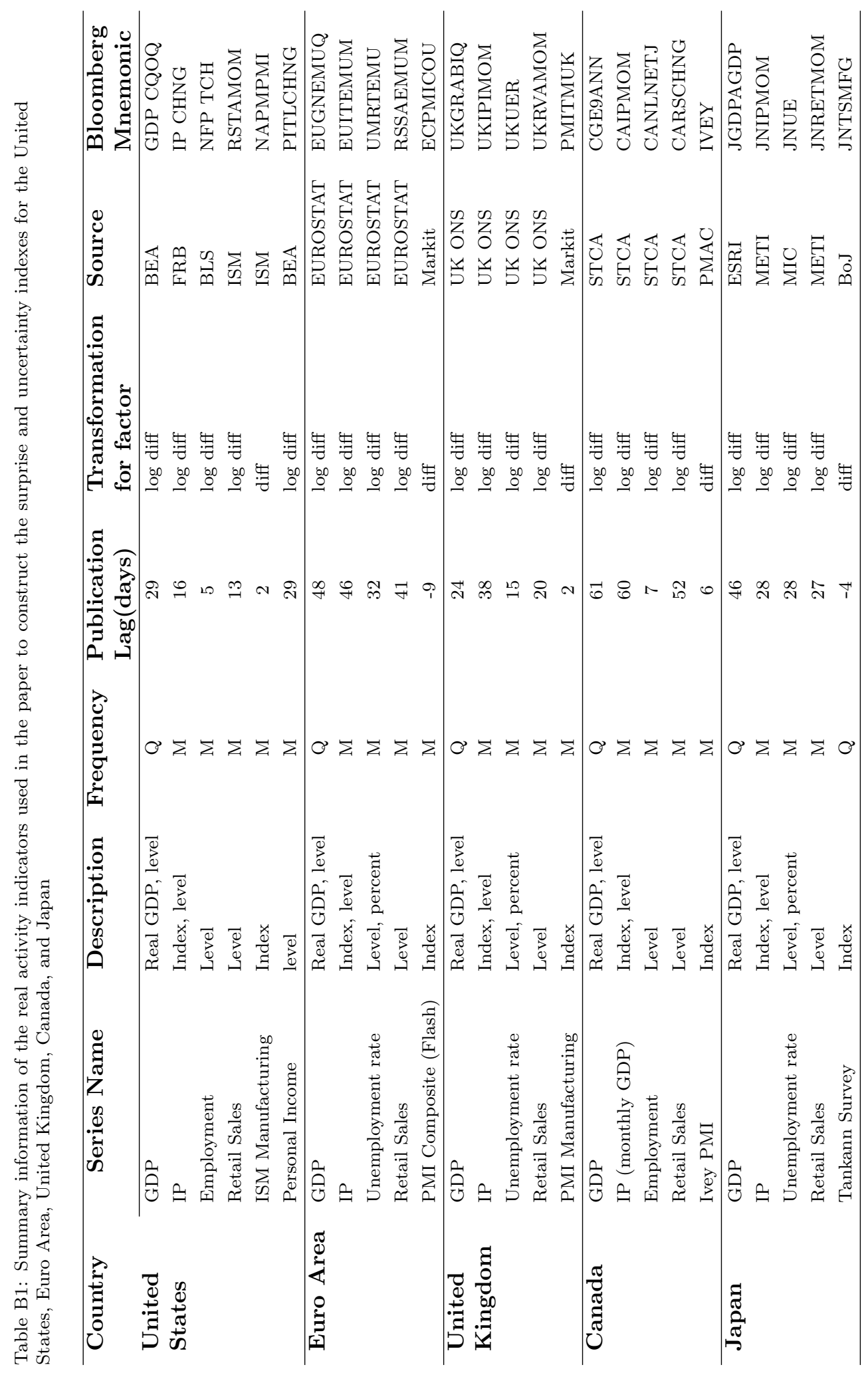


Table B2: Average cumulative weights for each indicator used to construct the surprise index. For comparability across countries, weights are standardized so that the sum of all weights in each country is equal to 1 . The average is computed over the entire sample.

\begin{tabular}{lccccc}
\hline & $\begin{array}{c}\text { United } \\
\text { States }\end{array}$ & $\begin{array}{c}\text { Euro } \\
\text { area }\end{array}$ & $\begin{array}{c}\text { United } \\
\text { Kingdom }\end{array}$ & Canada & Japan \\
\cline { 2 - 6 } GDP & 0.03 & 0.07 & 0.11 & 0.00 & 0.01 \\
IP & 0.36 & 0.39 & 0.46 & 0.02 & 0.53 \\
Employment/Unemployment & 0.26 & 0.26 & 0.27 & 0.91 & 0.20 \\
Retail Sales & 0.18 & 0.18 & 0.11 & 0.01 & 0.14 \\
PMI & 0.06 & 0.10 & 0.05 & 0.04 & 0.12 \\
Personal Income & 0.10 & & & & \\
\hline
\end{tabular}

Table B3: Correlation between the uncertainty measure and the implied and realized volatilities for each country.

\begin{tabular}{lccccc}
\hline \multicolumn{1}{l}{ Correlation of Uncertainty vs: } & & & \\
& $\begin{array}{r}\text { United } \\
\text { States }\end{array}$ & $\begin{array}{c}\text { Euro } \\
\text { area }\end{array}$ & $\begin{array}{c}\text { United } \\
\text { Kingdom }\end{array}$ & Canada & Japan \\
\cline { 2 - 5 } Implied Volatility & 0.52 & 0.11 & 0.35 & 0.32 & -0.01 \\
Realized Volatility & 0.53 & 0.11 & 0.31 & 0.33 & 0.06 \\
\hline Correlations are all significant except in the case of Japanese uncertainty vs. implied volatility.
\end{tabular}


Figure A1: +/- one standard error confidence interval for the real-activity uncertainty shock and the VIX

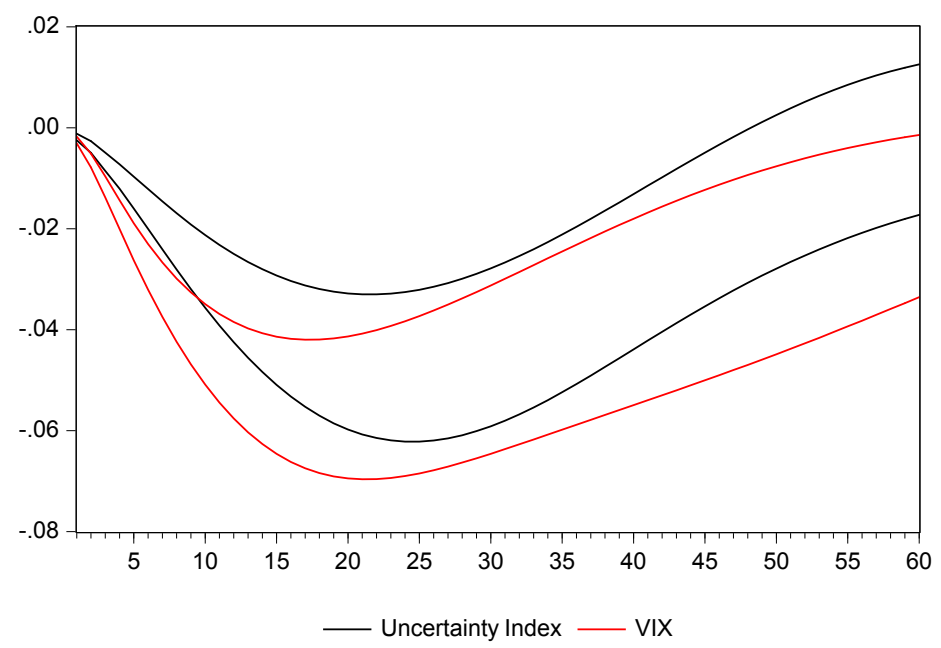

